DOI 10.1515/linpo-2016-0013

\title{
Synchronic and diachronic aspects of valency-reducing devices in Oceanic languages
}

\author{
Katarzyna Janic \\ Department of Comparative Linguistics, University of Zurich \\ e-mail: katarzyna.janic@univ-lyon2.fr
}

\begin{abstract}
Katarzyna Janic. Synchronic and diachronic aspects of valency-reducing devices in Oceanic languages. The Poznan Society for the Advancement of Arts and Sciences, PL ISSN 0079-4740, pp. 151-188

This paper sketches out valency-reducing devices available in Oceanic languages. The Proto-Oceanic prefix *paRi- and suffix *-akin[i] are specifically the focus of the discussion, being approached from both synchronic and diachronic perspectives. I explain the currently attested functions performed by the reflexes of these two morphemes by assuming that the evolution went in a particular direction: from a very general function to a more specialized, concrete one. Among different functions performed by the reflexes of *paRi- and *-akin [i] within the valency-reducing domain, I will show that the antipassive has not been fully recognized and properly designated in linguistic descriptions of the Oceanic languages yet.
\end{abstract}

Keywords: Oceanic languages, valency, plurality of relations, detransitivization, antipassive

\section{Introduction}

The question of valency and valency-changing devices in Oceanic languages has been extensively discussed in the literature (Ozanne-Rivierre 1976; Moyse-Faurie 1983, 2007, 2008, 2016, 2017; Schlie 1983; Lichtenberk 1985, 1991, 2000, 2007, 2008: 54-163; Schütz 1985; Dixon 1988: 45-51; Mosel \& Hovdhaugen 1992: 693-774, 720-741; B. Evans 2003: 301-309; Davis 2003: 110-178; Bril 2005; Naess 2013; among many others). While some of the scholars have investigated it diachronically with the aim to reconstruct these devices within the Proto-Oceanic system (Harrison 1982; B. Evans 2003: 171-300; Pawley 1973, etc.), the others have focused on their synchronic distribution alone. Within the valency-changing domain, there are two morphemes that have earned special attention among the Oceanists i.e. the prefix *paRi- and the suffix *akin[i]. It is commonly assumed that the reflexes of these two affixes can function as derivational markers with the possibility to reduce the initial value of the verbal valency. But as far as the functions performed by these two morphemes are concerned, the situation is less stable as the reflexes of *paRi- and *akin[i] have naturally not developed the same variety of 
functions in all Oceanic languages. In addition, there is one function, i.e. the antipassive one, that poses problems because it has received different treatments from individual authors. I will show that in many linguistic descriptions of Oceanic languages the existence of the antipassive has either been neglected or not fully acknowledged, being discussed under different labels. Nevertheless, the presence of this function is irrefutable and should be included in the account of different functions performed nowadays by the reflexes of *paRi- and *akin[i]. Given how much progress has been made recently in the study of linguistic diversity of Oceanic languages, it is high time to put the category of antipassive on the Oceanic agenda and to recognize its existence in these languages.

The aim of this paper is to contribute to the general discussion on valency-reducing devices available in the Oceanic languages with special attention given to the reflexes of *paRi- and *akin[i]. This will allow me to outline a new typology of functions expressed by these two affixes extended by the antipassive use. This study has been inspired by Lichtenberk's $(1985,2000)$ papers, which I use as an important point of reference for my analysis of the prefix *paRi-. But it differs from them to a large extent as explained in $\S 3$ and $\S 5.1$. Reference grammars, grammatical sketches and articles constitute the main source of data collection. Building on Lynch et al. (2002), each language, when mentioned for the first time, is accompanied by the name of the lowest subgrouping to which it belongs. The name of its first-level sub-classification is provided on a regular basis. For better understanding of examples, glosses have been harmonized, conforming to the Leipzig Glossing Rules (2015).

The present study consists of four parts and is organized as follows. $\$ 2$ sketches out the genealogical classification of the Oceanic languages as well as briefly summarizes valency-changing patterns attested in these languages. A description of origins of *paRiand $*_{\text {-akin }}[i]$ and functions their reflexes performed within the valency-reducing domain are provided in $\S 3$ and $\S 4$ respectively. The last section approaches diachronic aspects of these two morphemes, positing their plausible pathway of evolution (\$5). Concluding remarks are offered in $\S 6$.

\section{Oceanic languages}

\subsection{Genealogical affiliation}

The Oceanic languages belong to the Austronesian family, which comprises approximately 450 languages - about half of the Austronesian family (Ross 2004: 492). In terms of the geographical distribution, Austronesian languages are widely spread, extending from Madagascar, through Indonesia, the Philippines and Taiwan into the Pacific as far as New Zealand, Hawai'i and Easter Island. Oceanic languages are spoken mainly in the islands of the Pacific Ocean, in the northern coast of Papua New Guinea, Solomon Islands, Vanuatu, New Caledonia, Fiji, Polynesia, Bismarck Archipelago, Bougainville, and most of Micronesia. Building on Lynch et al. (2002: 878-889), Table 1 illustrates the major grouping along with the first three-level subgrouping of the Oceanic languages with the corresponding languages, which are subject to present discussion. The selection 
of languages was motivated by the results that emerged from my doctoral dissertation (Janic 2013). This inventory and the corresponding data were taken as a starting point for the present study and subsequently extended by new findings. Appendix A contains a list of the consulted, first-hand sources of the cited languages.

Table 1: Family grouping of the cited Oceanic languages

\section{Major grouping: YAPESE}

Language: Yapese

Major grouping: CENTRAL EASTERN OCEANIC

First level: Central Pacific Linkage

Second level: East Central Pacific Linkage

Third level: Eastern Fijian Linkage:

Languages: Boumaa Fijian, Standard Fijian

Third level: Polynesian Family:

Languages: East Futunan, Tongan

First level: Micronesian Family

Second level: Nuclear Micronesian Family

Third level: Central Micronesian Family:

First level: Southeast Solomonic Family

$$
\text { Languages: Woleaian, Mokilese }
$$

Second level: Longgu/Malaita/Makira Family

Third level: Longgu:

Language: Longgu

Third level: Malaita/Makira Family:

Language: Toqabaqita (North Malait)

First level: Southern Oceanic Linkage

Second level: Nuclear Southern Oceanic Linkage

Third level: South Efate/Southern Melanesian Linkage:

Languages: Iaai, Drehu, Nengone, Nêlêmwa

Second level: Northern Vanuatu Linkage

Third level: Ambae-Maewo Family:

Language: North-East Ambae

\section{Major grouping: WESTERN OCEANIC LINKAGE}

First level: Meso-Melanesian Cluster

Second level: New Ireland/Northwest Solomonic Linkage

Third level: St. George Linkage:

Languages: Hoava, Kokota, Roviana, Ughele, Zabana

Third level: Tungag-Nalik Family:

Languages: Kara, Tungag (Lavongai), Tigak

First level: North New Guinea Cluster

Second level: Schouten Linkage

Third level: Manam Linkage:

Language: Manam 


\subsection{General characteristics of valency-changing patterns}

This section provides a brief overview of linguistic strategies available in Oceanic languages that are responsible for valency change. Given that the notion of valency is related to such terms as like transitivity, (core) argument, argument structure and that these terms receive different treatments in the literature, their explanation is required prior to the empirical investigation.

Inspired by Lazard (1994), Creissels (2016) designates syntactically transitive constructions as having two core arguments: A and P, both encoded like agent and patient of core transitive verbs respectively. By contrast, the syntactic counterparts of transitive constructions i.e. intransitive constructions are associated only with one core argument i.e. S (meaning "single"). The coding properties of S overlap with the ones related to the single argument of most mono-valent verbs. Distinguishing the noun phrase(s) as core argument(s) logically allows us to label all other remaining noun phrases of a construction as oblique phrases (Creissels 2016). Regarding the argument structure of verbs (or 'semantic valency'), this notion refers to the semantic roles assumed by the arguments (e.g. agent, patient etc.). By contrast, syntactic structure of verbs (also known as 'function structure' or 'syntactic valency') involves syntactic functions (e.g. subject, object etc.) performed by these arguments (Haspelmath \& Sims 2010: 234). Given the interaction between argument structure and syntactic structure of verbs, Creissels (2016) defines the notion of valency as the one referring to the semantic roles assumed by the arguments and the way they are mapped onto syntactic functions. Taking into account that valency can be either reduced or increased, Oceanic languages dispose various strategies to modify it. Example (1) illustrates one of them, in which valency is increased morphologically by an explicit verbal marker.

(1) Hoava (Meso-Melanesian Cluster; Davis 2003: 186)
$\begin{array}{lll}\text { a. Honi sa } & \text { kabasa. } \\ \text { leak ART:SG } & \text { house }\end{array}$
'The house leaked.'
$\begin{array}{lll}\text { b. Honi-a } & \text { sa } & \text { kabasa } \\ \text { leak-TR:3SG } & \text { ART:SG } & \text { house }\end{array}$

'(It) leaked into the house.'

Hoava, a New Georgian language from the Meso-Melanesian Cluster, distinguishes transitive verbs from intransitive ones by means of the suffix $-a$, (1b) (Davis 2003). The so-called object marker not only increases valency but also modifies the mapping of semantic roles onto syntactic functions of the verb 'to leak'. In (1a), the argument $s a$ kabasa 'the house' performs the subject function with the patient-like interpretation, while in (1b), the same argument fills the object slot, being assigned the semantic role of patient.

Longgu, a language from the Southeast Solomonic Family, also applies the affixal strategy to modify the verbal valency. By contrast to Hoav a (1), however, this modification is not triggered by a flexional morpheme i.e. an object marker, but by the derivational suffix $-s i$, example (2). 
(2) Longgu (Southeast Solomonic Family; Hill 1992: 64; B. Evans 2003: 12)
a. geni $e$ mae na
woman $3 \mathrm{sg}$ die PFV
'The woman is dead.'
b. $e$ mae-si-a malaria- $i$
$3 \mathrm{SG}$ die-TR-3SG malaria-SG
'He/she died of malaria.'

According to B. Evans (2003), in (2b) the intransitive verb mae 'to die' becomes transitive through the presence of the valency-increasing -si suffix. Equipped with this morphological material, the verb is now in a position to accept the P-argument malaria- $i$ 'malaria-SG' in the object function, which is further indexed on the verb through the suffix $-a$. The coding frame through which the verb 'to die' expresses the argument structure in (2a) and (2b) differs with regard to the presence vs. absence of $\mathrm{P}$ and marking of this argument on the verb.

Although a large number of Oceanic languages sets up a syntactic dichotomy between marked transitive and unmarked intransitive verbs (1-2), this correlation is far from being absolute, since there are languages which show a totally opposite situation. To illustrate this variation, B. Evans (2003) provides example (3) taken from North-East Ambae (Ambae-Maewo).

(3) N.E. Ambae (Southern Oceanic Linkage; Hyslop 2001: 319; B. Evans 2003: 12)
a. langi u vutu na matui
wind TEL uproot ACC coconut
'The wind uprooted the coconut tree.'
b. matui u me-vutu
coconut TEL ANTI-uproot
'The coconut tree has been uprooted.'

In (3a), a transitive verb vutu 'to uproot' is left unmarked, while its intransitive equivalent in (3b) carries a valency-decreasing derivational prefix me- (Davis 2003). This opposition is reflected by a different coding frame of a verb based on flagging: <NOM, ACC $>$ vs. $<\mathrm{NOM}>$.

In addition to the affixal strategies, which can be either inflectional (1) or derivationa 1 ( 2)-(3), Oceanic languages may also affect valency by applying specific (morpho-) syntactic mechanisms. Example (4) illustrates one of them.

(4) Kokota (Meso-Melanesian Cluster; Palmer 2009: 193)
a. manei n-e-ke ara
he RL-3.SBJ-PFV punch=1sG.OBJ I

'He punched me.'
b. manei n-e du dupa bla
he RL-3.SBJ RED punch LMT
'He was just punching.'

Example (4) illustrates reduplication in Kokota (Ysabel) from the Meso-Melanesian Cluster. Palmer (2009) discusses this mechanism within three different derivational strat- 
egies susceptible to modify valency in this language. According to the author, in this process a transitive verbal root is reduplicated to derive an intransitive verb. The resulting construction is semantically related to the transitive one as "reduplication idiosyncratically derives a valency-augmented bivalent form, although not a transitive but an experiencer verb" (Palmer 2009: 192). Building on the definition provided in this section, we can argue that in (4), reduplication does not modify the argument structure of the verb 'to punch'. In both instances $(4 a-b)$, the lexical meaning of the verb involves two participants i.e. a puncher (agent) and a person being punched (patient). Unlike the transitive ver b (4a), the reduplicated o ne (4b) cancels, however, the overt P realisation. Nevertheless, the involvement of this argument in the development of the event is still implied. Thus, exam ple (4b) expresses a semantically transitive event encoded by a syntactically intransitive verb where the coding properties of S manei 'he' coincides with the ones associated with A of the transitive construction. Data from Tigak (5), a New Ireland language from the Meso-Melanesian Cluster, provide further evidence of reduplication.

(5) Tigak (Meso-Melanesian Cluster; Beaumont 1979: 93)

TRANSITIVE INTRANSITIVE
a. nol-i 'think' $\rightarrow$
no-nol 'think'
b. vis-i 'hit him' $\rightarrow$
vis-vis 'fight'
c. kalum-i 'see it' $\rightarrow \quad$ kal-kalum 'look, appear'

The left column illustrates an inventory of transitive verbs, while the right left one shows their reduplicated intransitive equivalents. According to Beaumont (1979), detransitivization involves reduplication, which is typically partial in Tigak and which is, in this language, one of two ways of reducing valency. In addition to reduplication, the author also mentions verbal derivations in -ai, discussed in section 4.2 (see ex. 46).

Incorporation is another (morpho-)syntactic mechanism which modifies the verbal valency, particularly when the incorporated lexeme corresponds to the P-argument of transitive verbs. The relationship between incorporation and reduced valency is illustrated by example (6).

(6) Hoava (Meso-Melanesian Cluster; Davis 2003: 188)
a. Bao-i-a sa makariva sa keke igana.
spear-TR-3SG ART:SG boy ART:SG one fish
'The boy speared the fish.'
b. Bao igana sa makariva
spear fish ART:SG boy
'The boy speared fish.'

Davis (2003) reports that the object incorporation (or P-incorporation) is frequently encountered in Hoava. This type of alternation entails detransitivization with the indefinite, non-specific object interpretation of the P-argument. Regarding example (6) in particular, we can see that in the transitive clause (6a), the nominal phrase sa keke igana 'the fish' is encoded like the P-argument i.e. it is indexed on the verb by the $-a$ object 
marker. Additionally, the verb carries a transitive marker $-i$. The P-argument is highly referential open to the definite interpretation. The coding of A sa makativa 'the boy' involves a word order strategy, since the place of this argument is reserved directly after the verb. Mithun (1984: 849) discusses the alternation illustrated by example (6b) under composition by juxtaposition, which is prevalent in the Oceanic languages. It refers specifically to the construction in which $\mathrm{P}$ is moved to the post-verbal position, losing the ability of being accompanied by the definite article from the corresponding transitive predication. Juxtaposed to the verb, which is no more accompanied by the transitive marker $-i$, the P-argument and the verb form a tight and inseparable bind, forming an intransitive complex predicate. Moyse-Faurie (1985) labels a similar type of alternation in Drehu syntactic incorporation, due to the strong resemblance to the morphological incorporation i.e. the inseparable bind holding between the object and the verb. Contrary to the morphological incorporation, the one illustrated by exampl e (6) is not strengthened morphologically. Following Moyse-Faurie (1985), I will label examp le (6) as illustrating syntactic incorporation. Note that Creissels (2006: 16) also discusses a similar type of example in the Oceanic languages within the incorporation domain. ${ }^{1}$

\section{Proto-Oceanic prefix *paRi-}

The reflexes of *paRi- are widely attested in the Oceanic group. They are frequently employed to reduce the verbal valency with different semantic impact on the interpretation of the clause. In what follows, I will first briefly present the origin of this affix (§3.1). Then, I will explain how I understand the term plurality of relations relevant for the Proto-Oceanic prefix *paRi- (\$3.2). Finally, I will show how this notion is reflected in various functions within the valency domain performed nowadays by the reflexes of *paRi- (§3.3). Appendix B summarizes the distribution and various morphological realisations of this prefix in the investigated languages as well as the way the reflexes of this prefix are glossed by the respective authors.

\subsection{Diachronic origin of the Proto-Oceanic prefix *paRi-}

Regarding the diachrony of the prefix *paRi-, there is a common agreement among the Oceanists on the origin of this morpheme and the initial function it performed. There is a consensus that it was used to encode different types of events that all have the property of plurality of relations in common. Lichtenberk (2000: 57), who specifically raises this question, argues that "[...] in the Oceanic case, there is evidence that it was a plurality of relations that was historically the primary factor". This means that the author considers the notion of plurality of relations to be fundamentally associated with the proto-form *paRi-. This claim is confirmed by Blust (unpublished manuscript), who

1 See Davis (2003: 188-190) for a more detailed discussion on incorporation in Hoava. For an in-depth analysis of this phenomenon in Oceanic languages in general, consult Mithun (1984). 
reconstructs the prefix *paRi- in Proto-Eastern-Malayo-Polynesian as a marker of collective and reciprocal events (Lichtenberk 2000) (cf. §3.2). Pawley (1973: 150-151), who also discusses the origin of this prefix, regards it as a reciprocal marker, which encodes "mutual interaction between the entities denoted by the subject of the verb". The same author also observes that *paRi- was used to encode repetitive actions or actions carried out jointly by a number of participants: "unified or conjoined action by a plural subject, or repeated action by a singular subject, or unification of objects" (Bril 2005: 26). Even if scholars may differ with regard to the exact types of functions performed by*paRi-, what is important to observe is that functions potentially associated with this morpheme imply the notion of plurality of relations. Another important aspect, which is crucial for this study and which has been highlighted by Lichtenberk (2000: 32), is that "there are no grounds for postulating a reflexive-marking function" for the Proto-Oceanic prefix *paRi-.

\subsection{The notion of plurality of relations}

The notion of plurality of relations ${ }^{2}$ is grounded in the conceptual domain of the event structure of a verb and refers to different types of relationships holding between more than one participant. The analysis of this notion involves the notion of plurality of participants since it raises the questions of how and to what extent the participants interact among themselves. Events expressed by reciprocal, collective, chaining, antipassive and distributive types of verbs involve the plurality of participants for their development. Since all these events share the semantic component of plurality of participants, it is likely that they are encoded by the same morphological material. Data from Oceanic languages support this observation. Nevertheless, I argue that as long as the notion of plurality of relations entails the plurality of participants, this correlation is unidirectional since the plurality of participants does not necessarily entail the plurality of relations, as it will be shown with regard to distributive events.

By definition, the notion of plurality of relations is related to events that require more than one participant for their development. A good example of such an even is a prototypical reciprocal event, expressed by the verb 'to kiss'. It involves two participants linked by a pair of inverse relations: $\mathrm{A} \rightarrow \mathrm{B}$ and $\mathrm{B} \rightarrow \mathrm{A}$. Each arrow binds the initiator of the event with the endpoint participant on which the action is performed and with which the initiator is not co-referred. The definition of reciprocal events with more than two participants is less straightforward. For instance, the clause The children said hello to each other, which illustrates this type of situation, does not necessarily imply that all children said hello to each other but that only a sizeable proportion of them did it (Creissels

${ }^{2}$ Lichtenberk (1985) is one of the first linguists discussing the notion of plurality of relations in detail in the literature. His investigation differs, however, from the present one in two important respects. Firstly, the author explores this notion within the context of the typological analysis, while the present paper approaches it within the Oceanic languages alone. Secondly, Lichtenberk's (1985) investigation covers events which do not necessarily involve a plurality of participants (e.g. reflexive), while this one targets only those the development of which requires the engagement of more than one participant. 
2016). An increase in the number of participants also increases the chance of triggering non-reciprocal events (cf. Dalrymple et al. 1998). This can be illustrated by chaining events defined as "a kind of chain of paired relations in an ordered series of participants" (Kemmer 1993: 100). The term chaining was introduced by Lichtenberk (1985: 24-26) with reference to Toqabaqita (Central North Malaita) and defines the action performed in chain, which is conceived as a unique, not-reciprocal process, expressed, for example, by the verb 'to follow'. An important characteristic of chaining-type events is that they are composed of temporal sub-events with a chain of paired relations. Schematized as A $\rightarrow$ $\mathrm{B} \rightarrow \mathrm{C}$, such events involve at least three participants: $\mathrm{A}, \mathrm{B}$ and $\mathrm{C}$ and two relations $\mathrm{A} \rightarrow \mathrm{B}, \mathrm{B} \rightarrow \mathrm{C}$. This means that each participant, except for the first and the last one, acts as the initiator in one relation and as endpoint in the second relation, which is of the same type. Thus, with regard to the chaining-type events, the multitude of participants logically entails the plurality of relations. The collective event is another example illustrating this correlation. Schematized as: $[\mathrm{A} \rightarrow, \mathrm{B} \rightarrow, \mathrm{C} \rightarrow]$, the participants involved in this event act as a group. A good candidate for expressing the collective-type event is the verb 'to gather' (Heine \& Miyashita 2008: 190). Each participant is associated with the arrow, which stands for the action he or she performs. Since the participants form a collective group, this means that they co-operate together and that they are not totally self-sufficient in performing the action. The key feature of this event is togetherness, which implies the mutual dependence among the participants. This subsequently implicates that each of the participants plays a double role, the one of the initiator and the one of the companion to another participant. Since the affectedness is not a relevant property for collective events, none of the participants is conceived as the endpoint. Closely related to collective events are distributive ones, expressed by the verb meaning 'to separate' (Heine \& Miyashita 2008: 190), or by the clause 'they [each] walked past their fellow' (Evans 2008: 51). Distributive events can be schematized as collective ones, with one important difference, viz. the individual participants act independently. This can be conventionally indicated by the lack of the square brackets: $\mathrm{A} \rightarrow, \mathrm{B} \rightarrow, \mathrm{C} \rightarrow$. The notion of independence logically cancels the idea of cooperation among the participants, which triggers the existence of specific relationships among them. The participants are assigned only one role i.e. the one of the initiator and they act independently from each other. Thus, the notion of plurality of relations does not hold for distributive events. Since in this study, I am interested in the events characterized by the plurality of relations, distributive events will not be subject to further discussion. Finally, the notion of plurality of relations can also be captured within antipassive events. However, it does not necessarily result from the plurality of participants understood as a group of people consisted of more than two persons, but from the repetition of the action performed over time. Prototypical antipassive-type events involve two participants: the initiator who acts on a distinct entity, the endpoint participant. This can be schematized as: A $\rightarrow$ B implying one relation, where the transfer of the action from A to B participants is unidirectional. But as I have observed with reference to many languages (e.g. Indo-European, Oceanic, Turkic, Bantu languages, Janic 2016), the antipassive frequently entails an aspectual change of an action with habitual, iterative, generic and/or repetitive interpretations. By default, such actions involve a plurality of successive events and so the plurality of 
$\mathrm{A} \rightarrow \mathrm{B}$ relation. In other words, the notion of plurality of relations is not primarily triggered by the plurality of participants, though the later was the preliminary condition for the former to come into being.

Events sharing the property of plurality of relations (e.g. reciprocal, collective, chaining and antipassive) have a semantic affinity. From the conceptual-semantic point of view, they are more complex than the ones characterized by the plurality of participants alone (e.g. distributive events). Their complexity results from the requirement of the relationship that needs to be held among the participants involved in these events. As far as reciprocal, collective and chaining events are concerned, the notion of plurality of relations is primarily driven by the plurality of participants. Regarding antipassive events, this notion is also triggered by the plurality of participants, but it is essentially driven by the repetitiveness of the same relation over time between two participants. Since distributive events involve the plurality of participants alone, they tend to be cognitively less complex and thus more relaxed on the conceptual-semantic level.

\subsection{Synchronic distribution of the reflexes of the prefix *paRi-}

\subsubsection{Reciprocal events}

The reflexes of the Proto-Oceanic prefix *paRi- can be employed to express the notion of reciprocity. With regard to the formal characteristics, this prefix tends to derive syntactically intransitive constructions where participants, sharing the semantic roles associated with $\mathrm{A}$ and $\mathrm{P}$ arguments in the corresponding transitive constructions, are now encoded as a single core argument. The reciprocal use of the reflexes of *paRi- is not necessarily the most frequent way to encode a mutual interaction between participants, though it is widely attested across various sub-grouping of the Oceanic languages, including the Southeast Solomonic Family, ex. (7).

(7) Toqabaqita (Southeast Solomonic Family; Lichtenberk 2007: 1552)

Kini bia wane kera kwai-'oli-i.
woman and man 3PL.FACT RECP-embrace-RECP
'The woman and the man embraced each other.'

In Toqabaqita (Central-North Malaita) (7), the prefix $k w a i{ }^{3}$ (a reflex of ${ }^{*} p a R i-$ ) encodes a prototypical reciprocal event with two participants: kini 'woman' and wane 'man' encoded as subject (Lichtenberk 2007). Each of them plays the same pair of roles vis-àvis each other i.e. they assume simultaneously the roles of agent and patient. Conceptually, the overall event can be decomposed into the temporal configuration of two subevents (or 'relations'): $\mathrm{A} \rightarrow \mathrm{B}$ and $\mathrm{B} \rightarrow \mathrm{A}$, in which the participants stand in a symmetrical relation to each other.

${ }^{3}$ The reciprocal morpheme $k w a i$ - co-occurs with the suffix $-i$ under specific conditions i.e. the latter typically combines with kwai- when the verbal base is disyllabic. See Lichtenberk (2008) for more details. 
Ex. (8) denotes another reciprocal event in Toqabaqita. Equipped with the same morphological material (the prefix $k w a i-$ ), this time the verb expresses a less prototypical reciprocal situation (or 'extended reciprocal') where the plurality of participants involves a group of people.

(8) Toqabaqita (Southeast Solomonic Family; Lichtenberk 2007: 1553)

To'a fuu kera firu keka kwai-kwa'e-i.

people that.down 3PL.FACT fight 3PL.SEQ RECP-hit-RECP

'The people down there are fighting, hitting each other.'

Lichtenberk (2007) underlines that the event of fighting in example (8) involves more than two reciprocal relations. In fact, at the conceptual level, the temporal decomposition of this event into the subevents is less clear than in relation to the prototypical reciprocal event expressed in (7). Even if it is more plausible that the blows of hitting are sequential rather than simultaneous, the construction per se expresses this event as a unified whole (Kemmer 1993). Typically for this type of events, the participants form a group of people where the question of whether all of them or only a sizeable proportion of them are/is involved in the event is left open.

The reciprocal use of the Proto-Oceanic prefix *paRi- is also attested in the Central Pacific Linkage in particular in Boumaa Fijian (Eastern Fijian), as shown by example (9).

(9) Boumaa Fijian (Central Pacific Linkage, Dixon 1988: 177; Bril 2005: 57)

Erau sa vei-'oti-vi ti'o gaa.

3DU ACT VEI-cut-PASS CONT still

'They (two) are cutting each other's hair.'

Example (9) illustrates a prototypical reciprocal event in Boumaa Fijian. Building on data from Dixon (1988), Bril (2005) observes that, in this language, the reciprocal construction is not only triggered by the prefix vei- (a reflex of *-paRi). The verb contains additionally another valency-changing marker, the passive suffix $v i$-. The presence of the latter specifies how the involved participants interact with each other: "Adding a passive suffix to a vei- form with this verb implies that each participant is alternately agent and patient, that is, each one does it to the other" (Dixon 1988: 178). Given the polyfunctionality of this morpheme, Bril (2005) takes a decision not to gloss the reflex of the prefix *-paRi in example (9).

The investigation of the use of the ${ }^{*} p a R i$ - reflexes within the domain of reciprocity can be further supported by data from the Southern Oceanic Linkage. Building on Moyse-Faurie (1983), Bril (2005) focuses inter alia on Drehu (Loyalty Islands), providing ex. (10).

(10) Drehu (Southern Oceanic Linkage; Moyse-Faurie 1983: 131-134; Bril 2005: 35)
a. atre $\rightarrow$ i-atre
'know' 'know each other'
b. aja $\rightarrow$ i-aja
'will, want' 'love each other'


(11) Drehu (Southern Oceanic Linkage; Moyse-Faurie 2008: 119)

$\begin{array}{lll}\text { angatr } & \text { a } & \boldsymbol{i} \text {-hnim } \\ \text { 3PL } & \text { IMPF } & \text { PREF-love }\end{array}$

'They are in love with each other.'

Bril (2005) mentions that in Drehu, the use of the prefix $i$-alone triggers two types of reciprocal events i.e. intrinsically (or 'naturally') reciprocal events and restricted reciprocal ones, limited to the presence of two participants (Moyse-Faurie 1983: 131-134). Moyse-Faurie (2008) points out the existence of a correlation between semantic verb classes and the reciprocal uses of the prefix $i$ - in this language viz. it expresses the notion of reciprocity with no additional morphological support, when combined with the non-dynamic verbs of emotion and perception, which by definition do not involve any movement or effort. This tendency is by no means categorical (see Moyse-Faurie 2008: 110). Nevertheless, it still reveals a strong tendency holding between a specific group of verbs and reciprocal use of the prefix $i$ - that is worth mentioning for Drehu. When the same prefix co-occurs, however, with the morpheme -keu, meaning together, the verb tends to express the extended reciprocal events, as shown in (12).

$\begin{array}{lllllll}\text { Drehu } & \text { (Southern Oceanic Linkage; } & \text { Moyse-Faurie } & \text { 2008: 110) } \\ \text { Itre lapa } & \text { a } & \text { i-xatua-keu } & \text { kowa la } & \text { ifaipoipo } \\ \text { PL } & \text { clan } & \text { IMPF } & \text { PREF-help-SUF } & \text { to } & \text { ART } & \text { wedding }\end{array}$

'The clans are helping each other for the wedding.'

A similar observation holds for Iaai (Loyalty Islands), another language from the Southern Oceanic Linkage. In Iaai, the prefix $i^{4}$ - rarely expresses reciprocal events alone, in particular prototypical ones. In most cases, in order to denote this action, a presence of an additional suffix $-k o ̈ u$, meaning together, is required, as shown by example (13) (Moyse-Faurie 2008).

(13) Iaai (Southern Oceanic Linkage; Moyse-Faurie 2008: 128)

ödrine $\quad$ u-hmehmë-köu

3PL.RSTR.PRS PREF-be.ashamed-SUF

'They are ashamed of each other.'

As mentioned subsequently by Moyse-Faurie (2008), when the circumfix $i-\ldots-k o ̈ u$ is employed in Iaai, specifically with the verbs of the antagonistic action, it triggers a collective reading, (14a). In such a context, the reciprocal interpretation is possible but under the condition that the circumfix additionally accommodates a pronominal object. Example (14b) illustrates this point.

(14) Iaai (Southern Oceanic Linkage; Moyse-Faurie 2008: 128)

$\begin{array}{ll}\text { a. Ödree } & \ddot{\boldsymbol{u}}-k u h w a-k \ddot{u} \text { } \\ \text { 3DU.PST } & \text { PREF-shoot-SUF }\end{array}$

'They shot together.'

${ }^{4}$ In some specific phonological environment, the prefix $i$ - is realised under the vowel $\ddot{u}[y]$ (Moyse-Faurie 2008). 


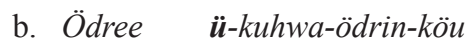

3DU.PST PREF-shoot-3PL.RSTR-SUF

'They shot at each other.'

\subsubsection{Antipassive events}

The reflexes of *paRi- also encode antipassive events. This term is not frequently - if at all - used in the description of Oceanic languages. This may be due to the weak development of antipassive function. Another plausible explanation is that the rare reference to the term antipassive results from the fact that it is traditionally related to the predominantly ergative languages. Consequently, in Oceanic languages, which often display the accusative alignment, if this phenomenon is reported, it is discussed under different labels. For example, many Oceanists (e.g. Davis 2003; Bril 2005) adopt the terminology coined by Lichtenberk (1991) to define the antipassive i.e. depatientive function. Moyse-Faurie (2008: 117, 2016) is one of the rare Oceanists who uses the term antipassive in the description of the Oceanic languages.

The Oceanic languages are homogenous as far as the antipassive use of the reflexes of *paRi- is concerned, viz. they reduce the verbal valency by deriving syntactically intransitive constructions, in which the P-argument is systematically dropped out from the verbal frame. In our sample, we did not find any antipassive construction in which $\mathrm{P}$ is demoted to oblique and only one in which this argument loses its properties of a core argument due to incorporation. The P-argument is typically omitted because its identity is not relevant for the event, being open to the generic, non-specific and/or non-referential interpretation. To illustrate this function, Lichtenberk (2007) provides example (15), glossing the respective prefix as depatientive.

$$
\text { Toqabaqita (Southeast Solomonic Family; Lichtenberk 2007: 1560) }
$$
a. Wane e laba-ta'i nau.
man 3SG.FACT harm-TR $1 \mathrm{SG}$
'The man harmed me.'

\section{b. Wane baa 'e kwai-laba-ta'i. \\ man that 3SG.FACT DEP-harm-TR}

'The man harms [people], damages / destroys [things].'

According to Lichtenberk (2007), example (15b) expresses a general characteristic of the agent, rather than a specific type of event, the latter being associated with the transitive clause (15a). To highlight this property, the paraphrase this man is the one who harms [people], destroys [thing] is equally acceptable for (15b). We can assume that the interpretation of general characteristic associated with the agent in the antipassive construction results from the repetition of the action 'to harm' (or 'relation' holding between $\mathrm{A}$ and $\mathrm{P}$ participants) over time to the extent it became a habit of the agent and subsequently its general characteristic.

In addition to the Southeast Solomonic Family, the antipassive use of *paRi- can also be reported for the Central Pacific Linkage in Standard Fijian (Eastern Fijian). Building 
on Schütz (1985), Bril (2005) provides ex. (16), pointing out that the prefix vei- (a reflex of *paRi-) does not necessarily trigger reciprocal and collective readings alone. While Schütz (1985) discusses the antipassive function under the section 'General, formalized: other active verbs [of vei-]', Bril (2005: 28), being inspired by Lichtenberk (2000), designates it as depatientive.

(16) Standard Fijian (Central Pacific Linkage; Schütz 1985: 208; Bril 2005: 57)

a Evuke-i au ${ }^{5}$.

'He helped me.' (on a specific occasion)

b. E dau vei-vuke.

3SG HAB VEI-help

'He often helps.' (as a general property)

We can extend the antipassive use of the prefix vei- in Standard Fijian by example (17).
Standard Fijian (Central Pacific Linkage; Schütz 1985: 208-209; Lichtenberk 2000: 43)
a $E$ a kati-a.
'He bit it.' (on a specific occasion)

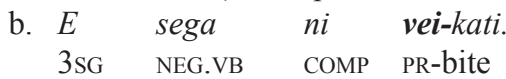
'It does not bite [people].' (said when discussing sharks)

According to (Schütz 1985), in Standard Fijian the prefix "vei- is used with active verbs (other than verbs of motion) to refer to general, formalized action, rather than to a specific instance" (Lichtenberk 2000: 43). To enhance this interpretative nuance, I argue that clauses (16-17) are equally open to the paraphrase: He has some tendency to help and This shark is the one who has no tendency/inclination/habit to bite respectively. Given that Lichtenberk (2000: 57) suggests that "in the Oceanic case, there is evidence that it was a plurality of relations that was historically the primary factor" that should be related to the Proto-Oceanic *paRi-, the author glosses the prefix vei- in example (17) as PR standing for "plurality of relations".

The existence of the antipassive function in Oceanic languages can be further supported by data from the Southern Oceanic Linkage; more specifically from the Southern Melanesian languages of the Loyalty Islands composed of three members: Drehu, Iaai and Nengone. Example (18) illustrates the most representative derivatives of the antipassive use in Drehu.

$$
\begin{aligned}
& \text { Drehu (Southern Oceanic Linkage; Moyse-Faurie 1983: 133; Sam 1995: 90; Bril 2005: 37) } \\
& \text { a xumuth } \rightarrow \text { i-xumuth } \\
& \text { 'pinch sb.' 'be a pincher = pinch sb.' } \\
& \begin{array}{ll}
\text { b. drei } & \rightarrow \quad \boldsymbol{i} \text {-drei } \\
\text { 'obey sb.' } & \text { 'be obedient = obey sb.' }
\end{array} \\
& \begin{array}{ll}
\text { c. } h e j & \rightarrow \text { i-heji } \\
\text { 'bite sb.' } & \text { 'be a biter = bite sb.' }
\end{array}
\end{aligned}
$$

\footnotetext{
${ }^{5}$ Example (16a) was provided without glosses.

${ }^{6}$ Example (17a) was provided without glosses.
} 
Bril (2005) discusses the function of the prefix $-i$ in (18), saying that it encodes generic actions and/or a (resulting) property of the subject participant. On a more specific level, we can see that this affix detransitivizes transitive verbs: $x$ umuth 'to pinch' (18a), drei 'to obey' (18b) and hey 'to bite' (18c), without modifying the semantic roles of the arguments. For instance, in (18a) the argument structure of the verb xumuth 'to pinch' and the one of the derived verb still implies agent and patient participants i.e. the person who kills and the one who is being killed, etc. Building on the behavioural properties of $P$ in the antipassive from Toqabaq ita (15) or Standard Fijian (16)-(17), we can assume that in Drehu, the P-argument is also left unexpressed, more specifically, it is syntactically suppressed. Examples (18b-c) are open to a similar analysis.

Haspelmath \& Müller-Bardey (2004: 1132), who investigate an analogous derivation in Lithuanian (labelling it potential deobjective), argue that this type of construction occurs only in generic and irrealis sentences. Findings from Iaai, (19)-(20), further support this observation.
Iaai (Southern Oceanic Linkage; Ozanne-Rivierre 1976: 218)
a. A-me oloü jee wanakat kuli.
3SG (process) bite the children the dog
'The dog bites the children.'
b. A-me ü-hülü kuli.
3SG (process) Ü-bite dog
'This dog bites i.e. this is a biting dog / this dog is a biter.'

(20) Iaai (Southern Oceanic Linkage; Ozanne-Rivierre 1976: 218)

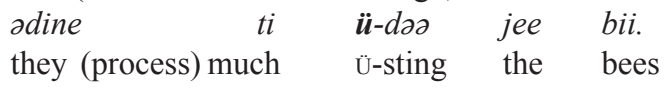

'The bees are very biting (they sting much).'

Building on the provided translations, we can assume that examples (19)-(20) ${ }^{7}$ also feature the predisposition of the agent to perform the action of biting and stinging accordingly. Contrary to Toqabaqita, Standard Fijian and Drehu, in Iaai, the antipassive use of the reflex of *paRi- can also serve to enhance a durative aspect of an action or its prolongation, as illustrated by verbal derivatives in example (21) (Ozanne-Rivierre 1976).
Iaai (Southern Oceanic Linkage; Ozanne-Rivierre 1976: 217)
a. aleü
$\rightarrow \quad \ddot{u}$-alü
'call sb. by making signs'
'make signs, action, which continues'
b. Ometto
'warn sb.'
$\rightarrow \quad \ddot{u}$-Ometto
'send messages, action, which continues'

Note that Ozanne-Rivierre (1976) does not really discuss the antipassive use of the prefix $\ddot{\boldsymbol{u}}$ - in (19)-(21) under any specific label. The author just mentions the aspectual and intransitivizing functions performed by this affix. Although it has not been mentioned explicitly in the literature, I will argue that like Drehu and Iaai, Nengone also attests an

\footnotetext{
${ }^{7}$ Examples (19)-(20) partially contain my own glosses.
} 
antipassive use of *paRi-, realized in this language as $i$-. This is most probably due to language contact. See example (22).

Nengone (Southern Oceanic Linkage; Bril 2005: 38)
Jaik nidi $\quad$ ci $\quad$ i-ule.
Jacques too.much DUR I-see
'Jacques stares too much [at people] (that's a characteristic of him).'

I designate example (22) as illustrating the antipassive since the semantic and syntactic impact of the prefix $i$ - on valency is comparable to the one typically associated with antipassive markers. In (22), the affix derives an intransitive construction without modifying the argument structure of the verb 'to see'. Moreover, it highlights the main characteristic of the agent.

In addition to the Central Eastern Oceanic languages discussed above, the antipassive is also attested in another major grouping of the Oceanic languages i.e. the Western Oceanic Linkage, more specifically in the Meso-Melanesian Cluster. As reported by Davis (2003) with reference to Hoava (Saint George), in this language, vari- (a reflex of *paRi-) is polyfunctional and among various functions, it also performs the depatientive (i.e. antipassive) function. Consequently, the author glosses it depatientive accordingly. Unlike in the Central Eastern Oceanic languages, here the prefix vari- derives the antipassive with the omitted P-argument in three different morphosyntactic contexts, as shown in (23-25) respectively.

(23) Hoava (Meso-Melanesian Cluster; Davis 2003: 137)

$\begin{array}{llll}\text { Vari-va-dugele sa } & \text { kasitona } & \text { sani. } \\ \text { DEP-CAUS-be.deaf ART:SG thing } & \text { DIST.SG } \\ \text { 'That thing can make [one] deaf.' } & \end{array}$

In (23), the prefix vari- is used together with another valency-changing morpheme i.e. the causative prefix va- (Davis 2003). The co-existence of two valency operators on the same verb, where one decreases it and another increases it, is typologically rare, though not entirely unheard of. Indeed, Stirtz (2012) reports a similar situation for Gaam, a Nilo-Saharan language.

(24) Hoava (Meso-Melanesian Cluster; Davis 2003: 137)

Kae vari-poni sa nikana.

NEG DEP-give ART:SG man

'The man is selfish.' lit. 'The man does not give [anything] to [anyone].'

Building on Lichtenberk (1991), Davis (2003) recognizes the depatientive function in the use of the prefix vari-, viz. in (24) the resulting construction is syntactically intransitive, though semantically it still expresses a transitive event. In addition, the implied patient is open to general, non-specific interpretations, typically associated with antipassive constructions.

Example (25) illustrates the third and last morphosyntactic environment associated with the antipassive use of the prefix vari- in Hoava. In this construction, the vari- der- 
ivation also occurs with the third person plural transitive suffix. According to Davis (2003), the presence of this suffix is typically associated with vari-verbs denoting reciprocal events. As mentioned by the same author " $[t]$ he use of the transitive suffix with depatientive is probably influenced by its use with reciprocals rather than any intended transitive function" (Davis 2003: 137).

(25) Hoava (Meso-Melanesian Cluster; Davis 2003: 137)

$\begin{array}{llll}\text { Vari-viraki } & \text { sa } & \text { sasaeri } & \text { heni. } \\ \text { DEP-itch.TR:3PL } & \text { ART:SG } & \text { leaf } & \text { this } \\ \text { 'This leaf can make [someone] itch.' } & \end{array}$

In Hoava, antipassives serve to avoid the overt specification of P. More precisely, according to Davis (2003), this construction is employed when the effects of the action are applicable to any person. However, if a specific body part of a person is affected, then the referent of this constituent can be overtly realized through object incorporation, as illustrated by example (26).

(26) Hoava (Meso-Melanesian Cluster; Davis 2003: 138)

$\begin{array}{llll}\mathrm{Na} & \text { huke, ninami vari-nhahu tia. } \\ \mathrm{ART} & \text { taro.leaf food } & \text { DEP-hurt } & \text { stomach }\end{array}$

'Taro leaves, food (which) can hurt stomachs.'

In example (26), the P-argument tia 'stomach' is juxtaposed to the verb, forming syntactic incorporation. This means that it does not retain the syntactic properties of a full-fledged noun phrase from the transitive construction. Bound by a verb, it can neither be accompanied by a modifier nor moved to a different position. In comparison to other Oceanic languages, the incorporation of Hoava (26) is atypical for two reasons. Firstly, contrary to many Oceanic languages, it may involve a verbal operator (but see also ex. [6]) (cf. Hopper \& Thompson 1980: 263; Palmer 1994: 194). Secondly, it is not used to express generic actions, typically associated with incorporation, but to indicate that actions target a specific part of a person. On a more general basis, P-incorporation constitutes another instance in which an argument is syntactically downgraded i.e. it loses its properties of a core argument. However, this form of demoting the core argument deviates from the one that is commonly associated with antipassives, viz. where downgrading results either in the omission of the P-argument or its realisation as oblique.

\subsubsection{Collective events}

Another use typically associated with the reflexes of *paRi- is the collective function, meaning to do something together. This function is attested in various subgroupings of the Oceanic languages, including the Southeast Solomonic Family. Example (27) illustrates this point. 
(27) Toqabaqita (South Southeast Solomonic Family; Lichtenberk 2007: 1559)

Kulu kwai-'adomi 'ana na'are-laa.

1PL RECP-help with cook-NMLZ

'Let's do the cooking together.' 'Let's co-operate in the cooking.'

In Toqabaqita (27), the collective reading is expressed by the morphological reciprocal construction, triggered by the prefix kwai- alone (Lichtenberk 2007). The presence of this affix serves to reduce the valency. It also indicates that the participants assume the roles of doer (or 'agent') and companion. They are all encoded as subject and the verb implies that the involved participants co-operate jointly in the event of cooking. The collective use of the reflexes of *paRi- can be further supported by data from the Meso-Melanesian Cluster, example (27).

(28) Hoava (Meso-Melanesian Cluster; Davis 2003: 136)

Vari-paqahi-ni-a gami sa gugusu.

COLL-leave-APPL-3SG PRO:1PL.EX ART:SG village

'We left the village together.'

(29) Hoava (Meso-Melanesian Cluster; Davis 2003: 136)

Kolo, na vari-nani tu ba gami ni.

friend NA COLL-fight REST EMPH PRO:1PL.EX DEM

'Friend, we were all fighting!' [with other people, not with each other].'

For Hoava, Davis (2003) reports two morphosyntactic contexts in which the prefix vari- triggers the collective interpretation. While in (28), the prefixed verb co-occurs with another valency-changing operator i.e. the applicative morpheme - ni, in (29) it couples with the verbal predicate nani 'to fight' alone. Regardless of the different morphosyntactic environment, these collective constructions share a common semantic denominator i.e. the plural subject.

At this stage of analysis is worth mentioning that ex. (29) can also be argued to trigger an antipassive reading. Although this has not been explicitly stated by Davis (2003), the proposed translation supports this observation. The verb 'to fight' is primarily associated with reciprocal events in which a sizeable proportion of participants assumes the roles of agent and patient i.e. they act together harming each other. However, the same event can also be construed differently. One can zoom in on one specific aspect of this event i.e. the fact that the participants act or co-operate together, where each of them assumes the roles of agent and companion. This naturally leads to collective reading, as proposed by Davis (2003). Given, however, that the line between collective and antipassive readings is very thin specifically within the context of transitive verbs, the collective reading of example (29): Friend, we were all fighting can also be conceived as the antipassive one in which the participants fight (together) somebody or against somebody, where the latter is backgrounded i.e. it is syntactically left unexpressed.

On a general basis, in the literature, the use of the term collective is not stable, being employed interchangeably with other labels such as associative, cooperative (Kemmer 1993: 98), mutual (Palmer 1994: 193), etc. Neither is there agreement among Oceanists. 
For example, Bril (2007: 1501) and Moyse-Faurie (2007: 1529), in order to label the collective event, employ the term sociative. For Boumaa Fijian (Eastern Fijian), Dixon (1988: 175) builds on the label collective, while Corston-Oliver (2002: 481) uses the term distributive for Roviana (New Georgia). Yet, some Oceanists mention that terms like collective and sociative are used interchangeably referring to the same type of event e.g. Moyse-Faurie (2008: 119). This lack of consistency is also noticeable in Frostad (2012), who glosses the collective use of vari- as distributive in Ughele (New Georgia) a language from the Meso-Melanesian Cluster. See example (30).

(30) Ughele (Meso-Melanesian Cluster; Frostad 2012: 162)
(...) meke poga vari-ghara-ni ghami.
and pound DISTR-gather-TR PRO:1PL.EX
'(...) and we pound it together (and thereby mix it).'

Even if Frostad (2012: 162) does not explicitly define the event expressed by (30) as collective, the author's description "several participants are acting or are acted upon together" clearly goes in this direction. Zabana (Ysabel), another language from the Meso-Melanesian Cluster, further confirms the unstable situation of the use of the collective term in the Oceanic languages. In this language, a prefix responsible for the collective function is glossed as reciprocal. However, Fitzsimons (1989: 112) explicitly mentions that it can also encode "actions undertaken jointly". To illustrate the collective function in Zabana, Lichtenberk (2000) provides example (31).

\begin{tabular}{|c|c|c|c|c|c|}
\hline$D i$ & vari-pu-purudu & ghini-u & palu & ghaseboro & $i d i$ \\
\hline 3PL:NONFUT & RECP-RED-run & VALEN:3SG-SEQ & two & woman & these \\
\hline ia & mamihi & & & & \\
\hline ART & wi.apple & & & & \\
\hline
\end{tabular}

Building on Churchward (1941: 20) and Milner (1972: 111-113), Schütz (1985) observes that in the Central Pacific Linkage, particularly in various dialects of Standard Fijian, the prefix vei- is labelled as a reciprocal marker since it is frequently encountered in this function. However, in some instances, it can also be used to encode the events in which the reciprocal interaction between participants is blurred, which often leads to more general i.e. the collective reading. Dixon (1988), who works specifically on Boumaa Fijian, mentions that in this language, the reflex of *paRi-, realized in this language also as vei-, conveys the collective meaning. The author argues that it is the collective rather than reciprocal function that should be primarily associated with this morpheme in Boumaa Fijian. This opinion stands in opposition to Schütz (1985) and Milner (1972), who consider reciprocity to be a basic function performed by the prefix vei- in Standard Fijian. To illustrate the collective function of vei- in Boumaa Fijian, Bril, building on Dixon (1988), provides example (32) with the unglossed vei- prefix. 
(32) Boumaa Fijian (Central Pacific Linkage; Dixon 1988: 177; Bril 2005: 57)

Erau sa vei-'oti ti'o.

3DU ACT VEI-cut CONT

'They (two) are involved in the activity of (hair) cutting.'

The collective function of the Proto-Oceanic prefix *paRi- is also common for languages affiliated to the Southern Oceanic Linkage, in particular, in Melanesian languages spoken on the Loyalty Islands. Moyse-Faurie (2008) provides a corresponding example from Iaai, (33), specifying that in this language, constructions derived by the reflex of *paRi- alone typically convey either collective meaning (33) or a middle one. Note that similarly to example (29), the one given in (33) can also trigger the antipassive reading.

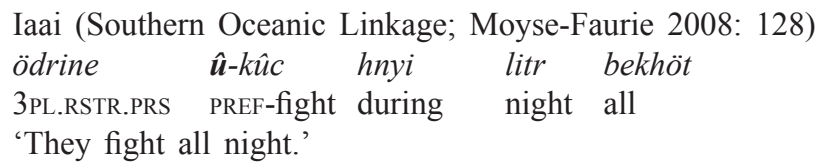

In Drehu (Loyalty Islands) (34), the collective function of the prefix $i$ - (a reflex of the morpheme *paRi-) is triggered in collaboration with the suffix -ny (Moyse-Faurie 1983).
Drehu (Southern Oceanic Linkage; Moyse-Faurie 1983: 134)
a. sue $\rightarrow$ i-sue-ny
'shout' 'shout together'
$\begin{array}{ll}\text { b. treij } & \rightarrow \quad \text { i-treije-ny } \\ \text { 'cry' } & \text { 'cry together' }\end{array}$
$\begin{array}{ll}\text { c. hmul } & \rightarrow \quad \text { i-hmuli-ny } \\ \text { 'sleep' } & \text { sleep together' }\end{array}$

In Nengone (Loyalty Island) illustrates a similar situation to Drehu. As explained by Moyse-Faurie (2008), in Nengone the prefix $e$ - (a reflex of *paRi-) expresses the collective function when combined with the suffix $-o$. In these two languages, the collective use of the circumfix (i.e. $i-\ldots-n y$ in Drehu, $e-\ldots-o$ in Nengone) is, however, not productive. These forms are either fossilized or encountered with a limited number of verbs. In general, Drehu and Nengone express collective events by employing an additional adverb ce and sese respectively, standing for "together", without additional marking on a verb (Moyse-Faurie 2008).

\subsubsection{Chaining events}

The clause The guests followed each other illustrates a chaining-type event, which in Oceanic languages may be expressed through the reflexes of the prefix *paRi-. Depending on the case, chaining events may either have temporal (35) or spatial configurations of the relations. 
Toqabaqita (Southeast Solomonic Family; Lichtenberk 2000: 35)

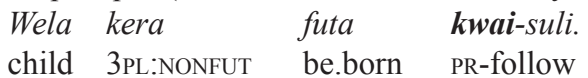

'The children (siblings) were born in quick succession (in successive years).'

In Toqabaqita (35), the chaining event is triggered by the complex form kwaisuli, diachronically related to a transitive verb suli meaning 'to follow' and to the prefix kwai(Lichtenberk 2000). Regarding the other first-level subgroupings of the Oceanic languages, the changing function is also attested in the Central Pacific Linkage, for example in East Futunan (36), in which chaining events are expressed by the circumfix $f e-\ldots-(C) a k i$ (Moyse-Faure 2008).

East Futunan (Central Pacific Linkage; Moyse-Faurie 2007: 1528)

$\begin{array}{llllll}e & \boldsymbol{f e} \text {-sipa-'aki } & \text { le } & \text { tānaki } & \text { o } & \text { moelaga. } \\ \text { IPFV } & \text { FE-be.crooked-RECP } & \text { ART } & \text { gathering } & \text { POSS } & \text { mat } \\ \text { 'Mats are not piled neatly.' } & & & & \end{array}$

Data from Southern Oceanic Linkage further support the chaining use of the modern *paRi-. In Nêlêmwa (North New Caledonia), the prefix pe-, which under some conditions co-occurs with the suffix $-i$, expresses a range of values with plurality of relations, including reciprocal, collective, distributed and chaining events, the latter illustrated by example (37) (Bril 2005).

$$
\begin{aligned}
& \text { Nêlêmwa (Southern Oceanic Linkage; Bril 2005: 47) } \\
& \text { Hla pe-oxo-i agu mahleeli. } \\
& \text { 3PL PE-follow-RECP people those.ANAPH } \\
& \text { 'These people walk in line.' }
\end{aligned}
$$

Contrary to reciprocal, antipassive and collective functions, the use of the reflexes of *paRi- to code chaining-type events naturally constitute a semantically restricted class of predicates. This explains a less frequent occurrence of this function of *paRi- within the Oceanic languages.

\section{The Proto-Oceanic morpheme *-akin[i]}

Section 4 deals with the Proto-Oceanic morpheme *-akin[i]. While $\S 4.1$ briefly summarizes its origin, $\S 4.2$ focuses on the synchronic distribution of the reflexes of the suffix *-akin [i] with the aim to explore the polyfunctional aspects of these reflexes within the valency-decreasing domain. Appendix $\mathrm{C}$ summarizes the distribution and morphological realisations of this suffix in the investigated languages and the way its reflexes are glossed by the respective authors. 


\subsection{Origin of the Proto-Oceanic morpheme *akin/i]}

Building on Pawley (1973) and Harrison (1982), B. Evans (2003) summarizes the

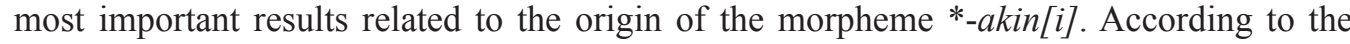
author, Pawley (1973) reconstructs $*_{-a k i n}[i]$ as a bound morpheme, realized as suffix within the verbal predicate. The choice of this morphological category was motivated by the fact that the modern equivalents of $*_{-a k i n}[i]$ still take the forms of suffixes. In addition, these forms are frequently equipped with the thematic consonant. Given that the place of the thematic consonant is reserved between a verbal stem and a following suffix, this motivated Pawley (1973) to reconstruct *-akin[i] as suffix. The same author assigns the suffix *-akin[i] a transitivizing function (Pawley 1973: 120). Labelled sometimes as transitive suffix, but mostly described as an applicative suffix, the form *-akin [i] should not be confused with another Proto-Oceanic transitive suffix * $*_{-}$. Both morphemes are said to occur in complementary distribution, being motivated by the semantic role of the P-argument. While the use of *-akin [i] involves cause, concomitant, instrument and beneficiary role assumed by the P-argument, the $*_{-i} i$ form is encountered in verbs where the $\mathrm{P}$-argument has a goal, stimulus and/or patient role.

On the basis of the synchronic distribution of the reflexes of the Proto-Oceanic *-akin[i], Harrison (1982) suggests a similar reconstruction of this form with one important difference: in his article on 'Proto Oceanic *akin[i] and the Proto-Oceanic Periphrastic Causative', the author provides evidence against the suffixal status of this morpheme. According to Harrison (1982), the distributional and functional patterns displayed nowadays by various reflexes of this morpheme, particularly in Micronesian languages, provide clear evidence in favour of the independent lexical verbal status of this form. As subsequently mentioned by the same author, it is only after the break-up of Proto-Oceanic that this morpheme developed into a bound suffixal form. Among various functions potentially performed by the Proto-Oceanic *-akin[i], Harrison (1982) highlights causativisation, which "reflected its pre-Proto-Oceanic use as a lexical verb occurring as the second (and final) verb in a serial verb construction that was a periphrastic causative" (B. Evans 2003: 175). The causative function of *-akin [i] is still performed by its modern equivalents in various Oceanic languages, including Yapese, Manam, Longgu, NorthEast Ambae, Boumaa Fijian, among others. In addition, Harrison (1982: 201-202) reconstructs the suffix *-akin[i] specifically for Proto-Micronesian languages as *-aki, suggesting that the reflexes of this morpheme derive intransitive verbs, triggering the agentless passive interpretation. The author also argues for the extension of the Proto-Micronesian agentless passive forms from the cause semantic, postulated for the Proto-Oceanic *-akin $[i]$.

\subsection{Synchronic distribution of the reflexes of the morpheme *-akin/i]}

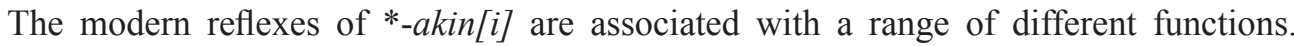
In addition to transitivization, they are also employed with reciprocal prefixes, as verbal prepositions and/or as trace elements. Additionally, in some Oceanic languages, these forms can also derive intransitive verbs from the corresponding transitive ones. The lat- 
ter function is observed in all languages of the Micronesian Family, in which the respective reflexes specifically show the agentless passive distribution (B. Evans 2003). Building on Sohn (1975), B. Evans (2003) provides an example (38) from Woleaian (Trukic-Ponapeic) to illustrate this function.
Woleaian (Micronesian Family; Sohn 1975: 245; B. Evans 2003: 135)
a. [ye] sa feshi-ng-i lag [filooras we]。
$3 \mathrm{SG} . \mathrm{SBJ}^{8}$ PFV pick-THC-TR DIR flower DEM
'He has picked the flower'.
b. [ye $]_{s}$ sa feshi-ng-eg lag [filooras we]
3SG.SBJ PFV pick-THC-PASS DIR flower DEM
'The flower has been picked up.'

According to B. Evans (2003), in Woleaian, the agentless passive construction is triggered by the passive marker $-e g$, diachronically related to the reflex of the ${ }^{*}$-aki form (Sohn 1975). The author subsequently specifies that in this language the agentless passive is lexically constrained, being compatible with a restricted number of transitive verbs.

Mokilese (Trukic-Ponapeic) is another Micronesian language which provides clear evidence for the capacity of the modern morpheme *-aki to decrease valency. Building on Harrison (1982), B. Evans (2003) associates the suffix, -ek (a reflex of $*_{-} a k i$ ) in Mokilese with the detransitivizing function, in particular with the agentless passive. Consequently, the author glosses this suffix as PASs (for "passive"), as shown by example (39).
Mokilese (Micronesian Family; Harrison 1982: 160; Evans 2003: 137)
a. ngoah okoj-da angenmajis-se
1SG light.TR-DIR match-DET
'I lit this match.'
b. angenmajis-se okoj-ek-da
match-DET light.TR-PASS-DIR
'This match has been lit.'

B. Evans (2003) describes that the suffix -ek does not always target the A-argument to reduce the valency. It happens that instead of A it downgrades P. Following Harrison (1982), B. Evans (2003) notes that in this particular context, the suffix -ek is used for unspecified objects and in incorporated object constructions. Example (40) confirms this observation. Given that these functions are rather atypical for the suffix -ek, B. Evans (2003) keeps glossing it as passive.
Mokilese (Micronesian Family; Harrison 1976: 160; B. Evans 2003: 137)
a. ngoah okoj-da angenmajis-se
1SG light.TR-DIR match-DET
'I lit this match.'
b. ngoah okoj-ek angenmajis
1SG light.TR-PASS match
'I am lighting matches.'

${ }^{8}$ The glosses of examples (38)-(40) have been provided by B. Evans (2003). 
I argue that the alternation in (40) displays the overall characteristic typically associated with antipassives, viz. the P-argument angenmajis-se 'match-DET' is demoted due to the derivational verbal marker $-e k$, while the argument structure of the verb is left unchanged, implying two participants: Agent and Patient. Demotion of P in the hierarchy of syntactic functions is realized through the syntactic incorporation of this argument into a verb. As a result, it has a decreased mobility and lacks the compatibility with the determiner -se from the transitive clause (40a). Moreover, unlike in the transitive construction, in the intransitive one, the demoted P-argument angenmajis 'matches' is open now to the non-specific interpretation (B. Evans 2003).

The analysis of the reflexes of $*$-akin $[i]$ as valency-decreasing markers is further supported by data from other Oceanic sub-groupings. In Kara (Tungag-Nalik) from the Meso-Melanesian Cluster, the reflex of *-akin [i], the suffix -ai, is open to target both A or P arguments (B. Evans 2003). To define these two functions, B. Evans (2003) adopts the glosses suggested by Schlie (1983), who recognises the A-downgrading and the P-downgrading functions of -ai under the label demotion. Example (41) first illustrates the agentless passive use of the suffix -ai, in which the P-argument, a kar aanabe? 'this car', is promoted to the subject position, while the pronominal A $r i$ is left unexpressed, though semantically this argument is still implied.

(41) Kara (Meso-Melanesian Cluster; Schlie 1983: 15-16; B. Evans 2003: 140)

$\begin{array}{llllll}\text { a. [ri] ves-an } & {[a} & k a r & \text { aanabe?] } & \text { pe Amerika } \\ \text { 3PL.SBJ make-EF } & \mathrm{NM} & \mathrm{car} & \text { this.here } & \text { PROG America }\end{array}$

'They made this car in America.'

b. [a karaanabe?] $]_{s}$ ves-ai ti Amerika

NM car this.here 3SG.SBJ make-DEM ABL America

'This car was made in America.'

Although in Kara the use of $-a i$ is primarily associated with the agentless passive function, B. Evans (2003) mentions, building on Schlie (1983), that this author also reports another detransitivizing function for -ai, leading to the P-argument demotion, (42). Even if neither Schlie (1983) nor B. Evans (2003) explicitly recognize the antipassive function in this use of $-a i$, the overall characteristics of the resulting construction remain in line with this observation.

Kara (Meso-Melanesian Cluster; Schlie 1983: 14; B. Evans 2003: 141)

a. [a malu] a fiit [a wai aapave] $]_{0} e$ vuax-e

NM wind 3SG.SBJ blow NM tree that.there and break-3SG.OBJ

'The wind blew that tree and broke it.'

b. [a malu $]_{s}$ a fit-ai se-na wai aapave $e$ vuax-e NM wind 3SG.SBJ blow-DEM CONC-3SG tree that.there and break-3SG.OBJ

'The wind blew against that tree and broke it.'

Example (42a) illustrates a transitive use of the verb fit 'to blow' with A and $\mathrm{P}$ arguments: a malu 'the wind' in the role of the Agent, and a wai aapave 'that tree' in the role of Patient (B. Evans 2003). We can further observe that in the detransitivized construction, (42b), P is syntactically downgraded to oblique position. Its peripheral status 
is signalled by the prepositional element sena. In both instances, (42a)-(42b), the verb fiit 'to blow' displays the same argument structure with the semantic roles of agent and patient. B. Evans (2003) notes that in addition to the syntactic function, the suffix $-a i$ also serves to defocus $\mathrm{P}$ i.e. it shifts the focus of the sentence from this argument to the agent of the action, which is conventionally indicated by the presence and absence of the square brackets in (42a)-(42b) accordingly.

B. Evans (2003) mentions that Kara has two other types of constructions characterized by P-demotion i.e. (43)-(44). Likewise, the morphosyntactic description of these constructions allows us to recognize them as representatives of antipassive predications (cf. Janic 2016).
Kara (Meso-Melanesian Cluster; Schlie 1983: 16; B. Evans 2003: 141)
a. na-[ne ${ }_{A}$ fi-n-[e] ${ }_{4}$ pa-na suga pe la stoa TOP-3SG ask-?-3SG.OBJ INS-3SG sugar PROG LOC store 'She / he asked him / her for sugar at the store.'
b. na-[ne $]_{s}$ fi-ai pa-na suga pe la stoa TOP-3SG ask-DEM INS-3SG sugar PROG LOC store 'She asked for sugar at the store.'

Derivation with -ai (43b) targets a recipient of the action, performing in this construction the object function (B. Evans 2003). Due to the presence of the verbal marker -ai, this argument is omitted from the clause. Being encoded by the 3sG object marker in a transitive construction (43a), in a derived one, it is no more indexed on the verbal form (43b).
Kara (Meso-Melanesian Cluster; Schlie 1983: 17; B. Evans 2003: 142)
a. na-se? tox-an a vua ina mamareai
TOP-who have-EF NM betelnut of buying
'Who has the betelnut for sale?
b. na-se? tox-ai vua ina mamareai
TOP-who have-DEM betelnut for buying
'Who has betelnut for sale?'

Finally, (44b) illustrates the verbal suffixation in $-a i$, which syntactically incorporates $\mathrm{P}$ a vua 'the betelnut' into the verb, rendering a transitive construction intransitive. Unlike the transitive one (44a), in which P triggers the specific interpretation, in the intransitive construction, this argument is open to a generic reading (B. Evans 2003). Note that the incorporated constituent is no more compatible with the noun marker $a$ present in the transitive predication and shows a reduced mobility with regard to the verb. They both constitute a frozen complex predicate.

The relationship between suffix $-a i$ and the detransitivizing function of the antipassive in Kara is further supported by data from Ross (1988: 377), illustrated in example (45). The author, who builds on findings described for Kara by Schlie (1983), admits that in general "the history and nature of [detransitivizing] function [of the reflexes of *-aki] needs further investigation". 
(45) Kara (Meso-Melanesian Cluster; Schlie 1983; Ross 1988: 377)
a. fiit 'blow something'
$\rightarrow$ fiit-ai 'blow'
b. lis-an 'take somebody with one' $\rightarrow$ lis-ai 'take with one'
c. fi-n- 'ask somebody'
fi-ai 'ask'

Ross (1988) compares the detransitivizing i.e. antipassive function of the suffix -ai in Kara with its equivalents from other Meso-Melanesian languages. More specifically, the author explores Tigak (46) and Tungag (47) languages from the Tungag-Nalik group, arguing for the noticeable functional parallel among them (B. Evans 2003).

(46) Tigak (Meso-Melanesian Cluster; Beaumont 1979: 93; Ross 1988: 377)

a. paloy-an- 'hear somebody' $\rightarrow$ palon-ai 'hear'

b. akauy-an- 'praise somebody' $\rightarrow$ akauy-ai 'give praise'

(47) Tungag (Meso-Melanesian Cluster; Stamm 1988; Ross 1988: 377)
a. $k e l$ 'dig'
$\rightarrow \quad k e l-k e l-a i l$ 'dig holes (for house posts)'
b. pala 'bind something' $\rightarrow$
pal-ai 'bind'
c. tak 'pull something' $\rightarrow$
tak-ai 'give a pull'

I argue that it is legitimate to claim with regard to examples (46)-(47) that the function of the suffix -ai is comparable to the one performed by the antipassive since this morpheme derives intransitive verbs from transitive ones without modifying the argument structure of verbs. For example, the verb tak 'to pull' $(47 \mathrm{c})$, when suffixed in -ai, still expresses the same action involving two participants: i.e. a person who pulls i.e. agent and the entity that is being pulled i.e. the patient. The referential properties of $\mathrm{P}$ of derived verbs may differ from the ones associated with $\mathrm{P}$ of transitive verbs, since its referent may be less specific, indefinite or it may not be overtly realized. Nevertheless, it is still present in the argument structure of the verb tak-ai 'give a pull'. An analogues analysis applies for all verbal derivatives in (45)-(47).

As far as the passive function of the reflexes of $*$-akin $[i]$ is concerned, the existence of this use has been commonly recorded by scholars of Oceanic languages. By contrast, the antipassive function posed some problems and it is typically discussed in the description of the Oceanic languages under different labels e.g. demotion, passive. This observation is particularly noticeable in B. Evans' (2003: 142) comments on Schlie's (1983) analysis of the suffix -ai: "Schlie's (1983) description of Kara -ai raises a number of questions about its use, but it is clear that $-a i$ is a detransitivizing reflex of Proto-Oceanic *akin [i]". Even if different uses of the reflexes of Proto-Oceanic *-akin [i] were not properly recognized and designated accordingly, what is of relevance is that it was fully acknowledged that the detransitivizing function of the reflexes of the suffix *-akin [i] was not limited to the (agentless) passive alone. 


\section{Diachronic development}

Section 5 approaches diachronic aspects of the Proto-Oceanic morphemes *paRi- and *-akin [i] and the way they have potentially extended their functions over time. Divided into two parts, the first part addresses the question of the functional extension of the prefix *paRi- (\$5.1), while the second part focusses on the functional development of the suffix *-akin[i] (§5.2).

\section{1. *PaRi- form}

Various reference grammars designate the reflexes of the Proto-Oceanic prefix *paRias reciprocal morphemes (cf. §3.3). Pawley (1973: 150-151), who reconstructed the Proto-Oceanic prefix *paRi- as a collective/associative, reciprocal, and iterative marker, mentions that it not only encodes (i) "mutual interaction between the entities denoted by the subject of the verb", but that it also marks (ii) "unified or conjoined action by a plural subject, or repeated action by a singular subject, or unification of objects" (Bril 2005). The same author subsequently specifies that labelling *paRi- as a reciprocal suffix is confusing, since "the strict reciprocal meaning was restricted to a subclass of verbs whose properties remain to be defined" (Bril 2005). Synchronically, many linguists kept subsuming different functions performed by the reflexes of the prefix *paRi- under the reciprocal term, considering it to be its primary function. Dixon (1988: 178) stands in a line with Pawley's observation with regard to the label reciprocal, building on a language-specific description, viz. Boumaa Fijian. The author states that in this language "to label [the prefix] vei- as reciprocal tends to obscure its other functions". The same author also argues that it is the collective function to do something together and not the reciprocal one to do something to each other that fully displays the real nature of the prefix vei- in Boumaa Fijian. This opinion stands in opposition to Schütz (1985) and Milner (1972), who argue for reciprocity to be the basic function of this prefix in Standard Fijian. Dixon (1988) also draws attention to a very important fact, namely that the vei- morpheme does not trigger middle interpretations in Boumaa Fijian. The prefix is only employed to encode events with plurality of participants. He subsequently suggests that the notion of reciprocity should rather be viewed as "a particular specification from its general - collective - meaning". Lichtenberk (1985) and Bril (2005) point out that Churchward (1941) arrived at a similar conclusion with regard to the term reciprocity in Standard Fijian. While Dixon (1988) suggests that collectivity should be regarded as the primary function of the modern *paRi- form, at least in Boumaa Fijian, without further explanation, Creissels (2006) provides a clear evidence, accounting why in languages with a morpheme coding reciprocal but not middle events, the notion of reciprocity should be regarded as a special instantiation of a more general - collective - function:

In such [languages], there are often indications that reciprocity can be explained through a process of specialization from the original function, which just served to encode events with plurality of participants, where the question of how each participant was involved in the event 
was left open. In other words, the forms with the initial meaning to do something together could specialize into a minor-type function to do something to each other (Creissels 2006: 38). ${ }^{9}$

Clear evidence for this hypothesis comes from Bantu languages, in which the reciprocal suffix -an is argued to be related to the comitative morpheme na meaning "together with" (Schladt 1998). According to Creissels (2006), this presupposes the existence of a stage in the evolution of these forms which expressed collective meaning (or 'co-participation' in Creissels' 2006, 2008 terminology) rather than reciprocity. This observation stands in line with Kemmer's (1993: 100) assumption according to which "the prototypical [reciprocal] situation is often subsumed under one or the other of what we might hypothesize to be more salient prototypes, either the direct reflexive or the collective". Given the range of meanings reconstructed by Pawley (1973) for the Proto-Oceanic form *paRi- and the fact that they all share the property of plurality of relations,$^{10}$ we can advance the hypotheses by Creissels (2006) and Kemmer (1933) with respect to the Oceanic languages. Instead of listing a range of functions presumably performed by the Proto-Oceanic*paRi- morpheme (Pawley 1973: 150-151), we can assume that the initial function of this prefix was very general, used to encode events sharing the property of plurality of relations. Building on Creissels (2016), who addresses the question of reciprocal-incorporation syncretism from a general perspective, we can presuppose in relation to Oceanic languages a similar hypothesis viz. that at the beginning the proto-form *paRiexpressed a general function related to the notion of plurality of relations where the assignment of the semantic roles to the participants of the event was motivated by the general knowledge of the world, lexical meaning of a verb and/or by the external factors such as discourse context. Subsequently, the Proto-Oceanic prefix *paRi- started to categorize the events characterized by the plurality of relations into more specific types such as reciprocal, antipassive, collective and chaining etc. This diachronic evolution is tentatively illustrated by the diagram in Figure 1.

This particular way of development might be favoured by languages due to cognitive principles, based on the assumption that the initial reciprocal meaning is not easily reducible to the current uses of the reflexes of the Proto-Oceanic prefix *paRi- such as antipassive, collective and/or chaining uses. By contrast, the extension from the general function (or 'meaning'), implying the plurality of relations alone, to the more specific one is easier to explain.

Due to the lack of historical data, the proposed hypothesis is highly speculative and by no means categorical and absolute in nature. Neither does it postulate that all the functions illustrated in Figure 1 actually existed simultaneously, being expressed by the proto-form *paRi-. For instance, Bostoen et al. (2015) argue for a late development of the antipassive in Bantu languages. Taking into account the strong resemblance between Bantu and Oceanic languages in terms of antipassive function and related morphological

9 My own translation.

10 Following Lichtenberk (2000), I assign the prefix *paRi- the initial value of plurality of relations. But contrary to the author, I do not discuss specific factors like low degree of individuation that could have potentially triggered the extension of this morpheme into antipassive, reciprocal and collective functions. 


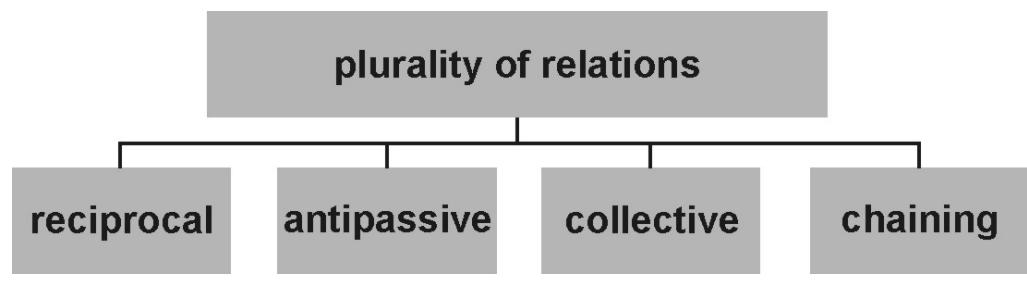

Figure 1. Functions of the form *paRi- at the interface of diachrony and synchrony

syncretism, a later development of the antipassive in the Oceanic languages cannot be entirely excluded.

\section{2. *-Akin[i] form}

In $\S 4.2$, I explored two functions performed by the reflexes of the form *-akin [i] i.e. agentless passive and antipassive. They were discussed in two Oceanic sub-branches i.e. the Micronesian Family with particular attention given to Woleaian and Mokilese, and in Meso-Melanesian Cluster, where the analysis was carried out for Kara, Tigak and Tungag languages. The passive-antipassive syncretism was specifically identified in Mokilese and Kara languages.

While the agentless passive is undoubtedly associated with the modern forms of *-akin [i], this is definitely not the case with the antipassive. In fact, none of the reference grammars that was consulted for the present study explicitly state the existence of the antipassive use of the reflexes of $*_{-a k i n}[i]$ in Oceanic languages. There are a few reasons that explain the weak recognition of this function in the Oceanic languages. The first one results from the fact that traditionally, the antipassive is associated with languages with ergative/absolutive alignment patterns (cf. Silverstein 1972). Taking into account that a large proportion of Oceanic languages shows nominative/accusative coding pattern, Oceanists have coined different terms to define this function. For instance, Schlie (1983) proposes the label defocusing-patient for the antipassive function of the suffix -ai in Kara, while B. Evans (2003) subsequently changed it into a demotion suffix. Yet, another author, Harrison (1976), provides unglossed examples of constructions with the suffix -ek in Mokilese that could be potentially identified as antipassive ones. Even if the author does not label them explicitly as antipassives, he openly recognizes two functions performed by the morpheme -ek typically associated with the antipassive i.e. this morpheme is used to encode unspecified or incorporated object. B. Evans (2003) takes the initiative to provide a grammatical description of the constructions delivered by Harrison (1976) in Mokilese i.e. passive and antipassives ones, glossing the suffix $-e k$ as passive, regardless of whether it performs passive or antipassive functions in the corresponding clauses.

As long as Oceanists differ with respect to the labels they coin to define the antipassive function performed by the modern reflexes of *-akin[i], they unquestionably recognize the (agentless) passive function of this morpheme. On a more advanced level, they all agree that the use of this morpheme boils down to the detransitivization of transitive 
verbs. Harrison (1982), who reconstructed the suffixal form *-aki for Proto Micronesian, argues, however, that the primary function of this morpheme is related to the domain of passive:

Reflexes of Proto-Micronesian *-aki derive intransitive verb forms from transitive stems, preserving a Proto-Oceanic final consonant. Common to all its reflexes is a resultant state or 'agentless passive' interpretation, though in Mokilese (and possibly Pingelapese, see Welley and Good 1976) the reflex -ek functions as a productive detransitivizing suffix in agentless passive, unspecified object, and incorporated object constructions. This wider use of reflexes of *aki appears to be an innovation from an original agentless passive. (Harrison 1982: 202)

The hypothesis according to which the agentless passive function extended its scope to other uses, including antipassives is debatable. This is probably due to the lack of potential implicational relationship between agentless passive and antipassive functions. The absence of this common semantic ground makes it difficult - if not impossible - to imagine the scenario according to which a language pushed a transition from (agentless) passive to antipassive. In other words, at the cognitive level, the reduction of (agentless) passive-type events into antipassive ones is difficult to explain and hence problematic. It seems that it is more prudent to consider a different scenario as illustrated by the diagram in Figure 2.

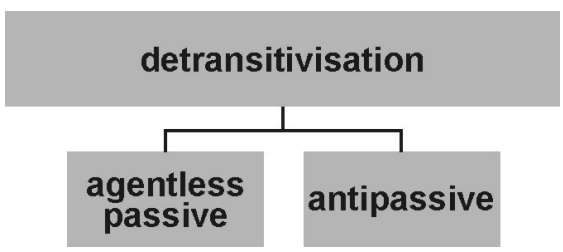

Figure 2. Functions of the form $*_{-a k i n}[i]$ at the interface of diachrony and synchrony

The evolutionary pathway of the form *-akin[i] illustrated in Figure 2 is based on the analogue principle as the one posited for the Proto-Oceanic *paRi- in $\S 5.1$ viz. it assumes the functional evolution departing from the very general and thus more abstract function into a more specific one. Building on this assumption, we can imagine that at the initial stage, this morpheme just performed a detransitivization function where the question of the semantic role assigned by the intransitive verb to its single core argument encoded as subject was left open. The external factors such as discourse context and/or knowledge of the world helped to determine the proper assignment of the semantic role to a S-argument of a detransitivised construction. In the second stage of this evolution, the morpheme specialized into various directions, performing more narrow-type functions, notably (agentless) passive and antipassive. ${ }^{11}$

${ }^{11}$ The transition from the general detransitivization function to more specific one was also posited by Creissels (2012) for the proto suffix $*_{-i}$ attested in Mande languages. 


\section{Conclusion}

The aim of this paper was to discuss the valency-reducing devices in Oceanic languages and the morphosyntactic patterns emerging from their application. The investigation into individual languages revealed that, in addition to the specific morphological affixes such as object marker (or 'transitive marker') and derivational valency operators, Oceanic languages also attest different mechanisms such as verbal reduplication and noun incorporation, which can equally modify valency. Among different valency-reducing operators, two morphemes, the Proto-Oceanic prefix *paRi- and the suffix *-akin[i], were specifically the focus of the discussion. Their analysis was approached from both synchronic and diachronic perspectives.

Synchronically, it has been illustrated that the reflexes of the Proto-Oceanic morphemes ${ }^{*} p a R i$ - and $\left.*_{\text {-akin }} i\right]$ are both polysemous with the ability to reduce verbal valency. Concerning the former in particular, I strengthened Lichtenberk' (2000) observation by showing that reflexes of the prefix *paRi- tend to encode different types of events in Oceanic languages, sharing the property of the plurality of relations. This common conceptual-semantic property allows us to account for the existence of implicational relationships among reciprocal, antipassive, collective and chaining-type events. With regard to the reflexes of the Proto-Oceanic morpheme *-akin [i], it has been shown that they might be employed in Oceanic languages, in particular in languages from the Meso-Melanesian Cluster and Micronesian Family, either to derive agentless passive or antipassive con-

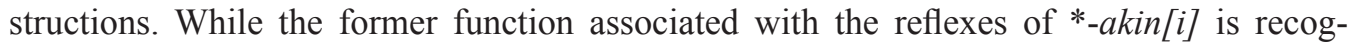
nized in the description of the Oceanic languages, their antipassive use has not been acknowledged under this term. A similar observation holds for the antipassive reflexes of the prefix *paRi-. Given that the function per se has been more or less acknowledged but discussed under different names (e.g. depatientive, demotion etc.) reflects a general problem of the lack of the standardization in the use of the term antipassive in the literature, in particular in languages with accusative case/agreement alignment pattern (cf. Janic 2016).

To explain the currently attested functions performed by the reflexes of *paRi- and *-akin[i], I have tentatively framed two hypotheses. They are based on the underlying assumption that the evolution goes in a particular direction: from a very general function to a more specialized one. This presupposes that the initial function of these two morphemes was more abstract where the assignment of the semantic roles to the participants of the event was driven by the external factors such as discourse context, lexical meaning of a verb and/or by the general knowledge of the world and that these two affixes were subsequently specialized in different directions. This functional-based approach to language change is further driven by a general assumption that if a grammatical morpheme extends its scope of functions following a particular direction, it is because some languages prefer this pattern of change over another one. It, however, by no means implies that it is the only possible way of change universally based and attested at the global scale. 


\title{
Acknowledgements
}

This project has received funding from the Swiss Government Excellence Postdoctoral Scholarship. The author is very grateful to the external and internal reviewers for their useful feedback. None of them should be held responsible for any remaining misconceptions or misunderstanding. I also thank my colleague, Nicole Nau, for her additional comments on an earlier draft and above of all for the wonderful collaboration on editing this thematic issue.

\begin{abstract}
Abbreviations
3 - third person; 1PL - first person plural; 3PL - third person plural; 1 PL.EX - first person plural exclusive; $1 \mathrm{SG}$ - first person singular; $3 \mathrm{SG}$ - third person singular; A - subject of transitive verb (Woleaian, Kara); ABL - ablative; ACC - accusative; ACT - actualizer; ANAPH - anaphoric; ANTI anticausative; APPL - applicative suffix; ART - article; CAUS - causative prefix; COLL - collective; COMP - complementizer; CONC - se prepostion (Kara); CONT - continuous; DEM - demotion (Kara); DEM - short demonstrative (Hoava, Woleaian); DEP - depatientive; DET - determiner; DIR - directional; DIST - distal demonstrative; DISTR - distributive; DU - dual; DUR - durative; EF - emphatic focus; EMPH - emphatic particle; FACT - factative; HAB - habitual; IMPF - imperfect; INS - instrumental; IPFV - imperfective; LMT - limiter; LOC - locative; NEG - negation; NM - noun marker; NONFUT - nonfuture; NMLZ - nominalizer; O - object of transitive verb (Woleaian, Kara); OBJ object (marker); PASS - passive; PFV - perfective; PL - plural; POSS - possessive; PR - plurality of relations; PREF - prefix; PRO - pronominal, pronoun (Hoava, Ughle); PROG - pe preposition (Kara); PRS - present tense; PST - past tense; RECP - reciprocal; RED - reduplication; REST - restrictive (particle); RL - realis; RSTR - restrictive; S - subject of intransitive verb (Woleaian, Kara); SBJ subject (marker); SEQ - sequencer, sequential (Toqabaqita); SG - singular; SUF - suffix; TEL - telic aspect; THC - thematic consonant; TOP - topic marker; TR - transitive; VALEN - valence; VB - verb.
\end{abstract}




\section{Appendix A}

Table 2: First-hand sources consulted for the cited languages

\begin{tabular}{|c|c|c|c|}
\hline Major grouping & First level grouping & Languages & Sources \\
\hline Yapese & & Yapese & Jensen (1977) \\
\hline \multirow{9}{*}{$\begin{array}{c}\text { Western Oceanic } \\
\text { Linkage }\end{array}$} & Meso-Melanesian Cluster & Hoava & Davis (2003) \\
\hline & & Ughele & Frostad (2012) \\
\hline & & Zabana & Fitzsimons (1989) \\
\hline & & Kara & Schlie (1983) \\
\hline & & Tigak & Beaumont (1979) \\
\hline & & Tungag (Lavongai) & Stamm (1988) \\
\hline & & Kokota & Palmer (2009) \\
\hline & & Roviana & Corston-Oliver (2002) \\
\hline & $\begin{array}{c}\text { North New Guinea } \\
\text { Cluster }\end{array}$ & Manam & Lichtenberk (1983) \\
\hline \multirow{16}{*}{$\begin{array}{l}\text { Central-Eastern } \\
\text { Oceanic }\end{array}$} & Central Pacific Linkage & Boumaa Fijian & Dixon (1988) \\
\hline & & Standard Fijian & Churchward (1941) \\
\hline & & & Schütz (1951) \\
\hline & & & Milner (1972) \\
\hline & & East Futunan & Moyse-Faurie (2007) \\
\hline & & Tongan & Churchward (1985) \\
\hline & Micronesian Family & Woleaian & Sohn (1975) \\
\hline & & Mokilese & Harrison (1976) \\
\hline & Southeast Solomonic & Toqabaqita & Lichtenberk (2008) \\
\hline & Family & Longgu & Hill $(1992,2011)$ \\
\hline & Southern Oceanic & Iaai & Ozanne-Rivierre (1976) \\
\hline & Linkage & Drehu & Moyse-Faurie (1983) \\
\hline & & & Sam (1995) \\
\hline & & Nengone & Tryon (1967) \\
\hline & & Nêlêmwa & Bril (2007) \\
\hline & & North-East Ambae & Hyslop (2001) \\
\hline
\end{tabular}




\section{Appendix B}

Table 3: Distribution and morphological realisations of the reflexes of Proto-Oceanic *paRi- in the investigated languages

\begin{tabular}{|c|c|c|c|c|}
\hline Language & Morpheme & Function & Glossed function & Examples \\
\hline \multirow[t]{2}{*}{ Toqabaqita } & $k w a i-\ldots-i$ & prot. $^{12}$ reciprocal & reciprocal & 7 \\
\hline & & extended reciprocal & reciprocal & 8 \\
\hline Boumma Fijian & vei- & prot. reciprocal & unglossed & 9 \\
\hline \multirow[t]{3}{*}{ Drehu } & $i-$ & reciprocal & unglossed & 10 \\
\hline & & extended reciprocal & prefix & 11 \\
\hline & $i-\ldots-k e u$ & extended reciprocal & $\begin{array}{l}(i-) \text { prefix } \\
(-k e u) \text { suffix }\end{array}$ & 12 \\
\hline \multirow[t]{2}{*}{ Iaai } & $i-\ldots-k \ddot{u} u$ & extended reciprocal & $\begin{array}{l}(i-) \text { prefix } \\
(-k \ddot{o} u) \text { suffix }\end{array}$ & 13 \\
\hline & & collective & $\begin{array}{c}(i-) \text { prefix } \\
(-k \ddot{o} u) \text { suffix }\end{array}$ & $14 \mathrm{a}$ \\
\hline Toqabaqita & kwai- & antipassive & depatientive & 15 \\
\hline \multirow[t]{2}{*}{ Standard Fijian } & vei- & antipassive & unglossed & 16 \\
\hline & & & plurality of relations & 17 \\
\hline Drehu & $i-$ & antipassive & unglossed & 18 \\
\hline Iaai & $i-$ & antipassive & unglossed & $19,20,21$ \\
\hline Nengone & $i$ - & antipassive & unglossed & 22 \\
\hline Hoava & vari- & antipassive & depatientive & $\begin{array}{l}23,24 \\
25,26\end{array}$ \\
\hline Toqabaqita & kwai- & collective & reciprocal & 27 \\
\hline Hoava & vari- & collective & collective & 28,29 \\
\hline Ughele & vari- & collective & distributive & 30 \\
\hline Zabana & vari- & collective & reciprocal & 31 \\
\hline Boumaa Fijian & vei- & collective & unglossed & 32 \\
\hline Iaai & $i$ - & collective & prefix & 33 \\
\hline Drehu & $i-$ & collective & unglossed & 34 \\
\hline Toqabaqita & kwai- & chaining & plurality of relations & 35 \\
\hline East Futunan & $f e-\ldots-' a k i$ & chaining & $\begin{array}{l}\text { (fe-) unglossed } \\
\text { (-'aki) reciprocal }\end{array}$ & 36 \\
\hline Nêlêmwa & $p e-\ldots-i$ & chaining & $\begin{array}{l}\text { (pe-) unglossed } \\
(i-) \text { reciprocal }\end{array}$ & 37 \\
\hline
\end{tabular}

12 The abbreviation prot. stands for prototypical. 


\section{Appendix C}

Table 4: Distribution and morphological realisations of the reflexes of Proto-Oceanic *-akin[i] in the investigated languages

\begin{tabular}{ccccc}
\hline Language & Morpheme & Function & Glossed function & Examples \\
\hline Woleaian & $-e g$ & passive & passive & 38 \\
Mokilese & $-e k$ & passive & passive & 39 \\
& & antipassive & passive & 40 \\
Kara & $-a i$ & passive & demotion & 41 \\
& & antipassive & demotion & $42,43,44$ \\
& & antipassive & unglossed & 45 \\
Tigak & $-a i$ & antipassive & unglossed & 46 \\
Tungag & $-a i$ & antipassive & unglossed & 47 \\
\hline
\end{tabular}

\section{References}

Beaumont, Clive H. 1979. The Tigak language of New Ireland (Pacific Linguistics). Canberra: Department of Linguistics, Research School of Pacific Studies, Australian National University.

Blust, Robert A. Austronesian comparative dictionary. (Unpublished manuscript.)

Bostoen, Koen \& Dom, Sebastian \& Segerer, Guillaume. 2015. The antipassive in Bantu. Linguistics 53(4). 731-772.

Bril, Isabelle. 2005. Semantic and functional diversification of reciprocal and middle prefixes in New Caledonian and other Austronesian languages. Linguistic Typology 9(1). 25-76.

Bril, Isabelle. 2007. Reciprocal constructions in Nêlêmwa (New Caledonia). In Nedjalkov, Vladimir P. (ed.), Reciprocal constructions, 1479-1509 (Typological Studies in Language 71). Amsterdam: John Benjamins Publishing Company.

Churchward, Clerk M. 1941. A new Fijian grammar. Fiji: Australasian Medical Publishing Company.

Churchward, Clerk M. 1985. Tongan grammar. Tonga: Vava'u Press.

Corston-Oliver, Simon. 2002. Roviana. In Lynch, Ross \& Malcolm, John \& Crowley, Terry (eds.), The Oceanic languages, 467-491 (Curzon Language Family Series 1). Richmond: Curzon.

Creissels, Denis. 2006. Syntaxe générale : une introduction typologique. 2, La phrase (Syntaxe Générale). Paris: Hermès Science.

Creissels, Denis \& Nouguier-Voisin, Sylvie. 2008. The verbal suffixes of Wolof coding valency changes and the notion of co-participation. In König, Ekkehard \& Gast, Volker (eds.), Reciprocals and Reflexives: Theoretical and Typological Explorations, 652 (Trends in Linguistics. Studies and Monographs 192). Berlin: De Gruyter Mouton.

Creissels, Denis. 2016. Transitivity, valency and voice. Paper presented at the European Summer School in Linguistic Typology. Porquerolles.

Davis, Karen. 2003. A grammar of the Hoava language, Western Solomons (Pacific Linguistics 535). Canberra: Pacific Linguistics, Research School of Pacific and Asian Studies, Australian National University.

Dixon, R. M. W. 1988. A grammar of Boumaa Fijian. Chicago: University of Chicago Press.

Dalrymple, Mary \& Kanazawa, Makoto \& Kim, Yookyung \& Mchombo, Sam \& Peters, Stanley. 1998. Reciprocal expressions and the concept of reciprocity. Linguistics and Philosophy 21. 159-210.

Evans, Bethwyn. 2003. A study of valency-changing devices in Proto Oceanic (Pacific Linguistics 539). Canberra: Pacific Linguistics, Research School of Pacific and Asian Studies, Australian National University. 
Evans, Nicholas. 2008. Reciprocal constructions: Towards a structural typology. In Koenig, Ekkehard \& Gast, Volker (eds.), Reciprocals and reflexives: Theoretical and typological explorations, 33-103 (Trends in Linguistics. Studies and Monographs 192). Berlin: De Gruyter Mouton.

Fitzsimons, Matthew. 1989. Zabana: A grammar of a Solomon Islands language. University of Auckland. (M.A. thesis.)

Frostad, Benedicte Haraldstad. 2012. A grammar of Ughele: An Oceanic language of Solomon Islands. Utrecht: LOT.

Geniušienè, Emma. 1987. The typology of reflexives (Empirical Approaches to Language Typology 2). Berlin: De Gruyter Mouton.

Harrison, Sheldon P. 1982. Proto Oceanic *aki(ni) and the Proto Oceanic periphrastic causative. In Halim, Amran \& Carrington, Lois \& Wurm Adolphe, Stephen (eds.), Papers from the Third International Conference on Austronesian Linguistics, 179-230. (Pacific Linguistics). Canberra: Department of Linguistics, Research School of Pacific Studies, Australian National University.

Harrison, Sheldon P. 1976. Mokilese reference grammar (PALI Language Texts). Honolulu: University Press of Hawaii.

Haspelmath, Martin \& Sims, Andrea D. 2010. Understanding morphology. 2nd ed. (Understanding Language Series). London: Hodder Education.

Haspelmath, Martin \& Müller-Bardey, Thomas. 2004. Valence change. In Booij, G. E. \& Lehmann, Christian \& Mugdan, Joachim (eds.), Morphologie: ein internationales Handbuch zur Flexion und Wortbildung, 1130-1145 (Handbücher Zur Sprach- Und Kommunikationswissenschaft $=$ Handbooks of Linguistics and Communication Science 17.2). Berlin: De Gruyter Mouton.

Heine, Bernd \& Miyashita, Hiroyuki. 2008. The intersection between reflexives and reciprocals: a grammaticalization perspective. In König, Ekkehard \& Gast, Volker (eds.), Reciprocals and Reflexives: Theoretical and Typological Explorations, 169-224 (Trends in Linguistics. Studies and Monographs 192). Berlin: De Gruyter Mouton.

Hill, Deborah. 1992. Longgu grammar. Australian National University. (PhD thesis.)

Hill, Deborah. 2011. Longgu grammar (Outstanding Grammars from Australia 4). Muenchen: LINCOM Europa.

Hopper, Paul J. \& Thompson, Sandra A. 1980. Transitivity in grammar and discourse. Language 56(2). 251-299.

Hyslop, Catriona. 2001. The Lolovoli dialect of the North-East Ambae language, Vanuatu (Pacific Linguistics 515). Canberra: Pacific Linguistics, Research School of Pacific and Asian Studies, Australian National University.

Janic, Katarzyna. 2013. L'antipassif dans les langues accusatives. Lyon: Université de Lyon.

Janic, Katarzyna. 2016. L'antipassif dans les langues accusatives (GRAMM-R. Études de Linguistique Française). Bruxelles: Peter Lang.

Jensen, John Thayer. 1977. Yapese reference grammar. Honolulu: University Press of Hawaii.

Kemmer, Suzanne. 1993. The Middle voice (Typological Studies in Language 23). Amsterdam: John Benjamins Publishing Company.

Lazard, Gilbert. 1994. L'actance. 1re éd. (Linguistique Nouvelle). Paris: Presses universitaires de France.

Lichtenberk, František. 1983. A grammar of Manam (Oceanic Linguistics Special Publications 18). Honolulu: University of Hawaii Press.

Lichtenberk, František. 1985. Multiple uses of reciprocal constructions. Australian Journal of lLinguistics 5(4). $19-41$.

Lichtenberk, František. 1991. Reciprocals and depatientives in To'aba'ita. Currents in Pacific linguistics: papers on Austronesian languages and ethnolinguistics in honour of George W. Grace, 171-183 (Pacific Linguistics. Series C 117). Canberra: Dept. of Linguistics, Research School of Pacific Studies, Australian National University.

Lichtenberk, František. 2000. Reciprocals without reflexives. In Frajzyngier, Zygmunt \& Curl, Traci S. (eds.), Reciprocals: Forms and Functions, 31-62 (Typological Studies in Language 41). Amsterdam: John Benjamins Publishing Company.

Lichtenberk, František. 2007. Reciprocals and related meanings in To'aba'ita. In Nedjalkov, Vladimir P. (ed.), Reciprocal constructions, 1547-1574 (Typological Studies in Language 71). Amsterdam: John Benjamins Publishing Company.

Lichtenberk, František. 2008. A Grammar of Toqabaqita (Mouton Grammar Library 42). Berlin: De Gruyter Mouton. 
Lynch, John \& Ross, Malcolm \& Crowley, Terry. 2002. The Oceanic languages (Curzon Language Family Series 1). Richmond: Curzon.

Malchukov, Andrej L. \& Comrie, Bernard (eds.). 2015. Valency Classes in the World's Languages (Comparative Handbooks of Linguistics 1.1-1.2). Berlin: De Gruyter Mouton.

Milner, George B. 1972. Fijian grammar. Suva (Fiji): Government Press.

Mithun, M. 1984. The evolution of noun incorporation. Language 60(4). 847-893.

Mosel, Ulrike \& Hovdhaugen, Even. 1992. Samoan reference grammar. Oslo: Scandinavian University Press: Institute for Comparative Research in Human Culture.

Moyse-Faurie, Claire. 1983. Le Drehu: langue de Lifou (îles Loyauté): phonologie, morphologie, syntaxe (Langues et Cultures du Pacifique 3). Paris: Société d'études linguistiques et anthropologiques de France.

Moyse-Faurie, Claire. 1985. Incorporation morphologique et incorporation syntaxique en drehu, Actances 1. 123-133.

Moyse-Faurie, Claire. 2007. Reciprocal, sociative, middle and iterative constructions in East Futunan. In Nedjalkov, Vladimir P. (ed.), Reciprocal constructions, 1511-1543 (Typological Studies in Language 71). Amsterdam: John Benjamins Publishing Company.

Moyse-Faurie, Claire. 2008. Constructions expressing middle, reflexive and reciprocal situations in some oceanic languages. In Koenig, Ekkehard \& Gast, Volker (eds.), Reciprocals and reflexives: Theoretical and typological explorations, 105-168 (Trends in Linguistics. Studies and Monographs 192). Berlin: De Gruyter Mouton.

Moyse-Faurie, Claire. 2016. Backgrounding the object in Oceanic languages: a comparison between three constructions relevant to antipassive. Paper presented at the Workshop "The crosslinguistic diversity of antipassives: function, meaning and structure" at the conference Societas Linguistica Europaea, Naples.

Moyse-Faurie, Claire, 2017. Reflexive markers in Oceanic Languages. In Studia Linguistica. Special issue on The world of reflexives: universal principles and a typology of variation, edited by Dimitriadis, Alexis \& Everaert, Martin \& Reuland, Eric, 107-135. http://onlinelibrary.wiley.com/doi/10.1111/stul.2017.71.issue-1pt2/issuetoc.

Næss, Åshild, 2013. From Austronesian voice to Oceanic transitivity: Äiwoo as the 'missing link'. Oceanic Linguistics 52(1). 106-124.

Nedjalkov, Vladimir P. 2007. Polysemy of reciprocal markers. In Nedjalkov, Vladimir P. (ed.), Reciprocal Constructions, 231-333 (Typological Studies in Language 71). Amsterdam: John Benjamins Publishing Company.

Ozanne-Rivierre, Françoise. 1976. Le iaai: langue mélanésienne d'Ouvéa, Nouvelle-Calédonie: phonologie, morphologie, esquisse syntaxique (Langues et Civilisations À Tradition Orale 20). Paris: Société d'études linguistiques et anthropologiques de France.

Palmer, Bill. 2009. Kokota grammar (Oceanic Linguistics Special Publications 35). Honolulu: University of Hawai`i Press.

Palmer, Frank Robert. 1994. Grammatical roles and relations (Cambridge Textbooks in Linguistics). Cambridge: Cambridge University Press.

Pawley, Andrew. 1973. Some problems in Proto-Oceanic grammar. Oceanic Linguistics 1 and 2. 103-188.

Ross, Malcolm. 1988. Proto Oceanic and the Austronesian languages of Western Melanesia (Pacific Linguistics 98). Canberra, A.C.T., Australia: Department of Linguistics, Research School of Pacific Studies, the Australian National University.

Ross, Malcolm D. 2004. The morphosyntactic typology of Oceanic languages. Language and Linguistics 5(2). 491-541.

Sam, Drilë L. 1995. Dictionnaire drehu-français (Lifou, Nouvelle-Calédonie). Nouméa: Centre territorial de recherche et de documentation pédagogique de Nouvelle-Calédonie.

Schladt, Mathias. 1998. Reciprocals in Bantu languages: a case of grammaticalization. Afrikanistische Arbeidspapieren 53. 5-25.

Schlie, Ginny. 1983. Individuation and topicality as indices of transitivity: Degrees of passive in Kara. Ukarumpa, Papua New Guinea: Summer Institute of Linguistics, ms. www.sil.org/pacific/png/abstract.as$\mathrm{p} ? \mathrm{id}=928474560366$.

Schütz, Albert J. 1985. The Fijian language. Honolulu: University of Hawaii Press.

Silverstein, Michael. 1972. Chinook Jargon: language contact and the problem of multilevel generative systems, part I. Language 48(2). 378-406. 
Sohn, Homin. 1975. Woleaian reference grammar (PALI Language Texts). Honolulu: University Press of Hawaii.

Stamm, Jospef. 1988. A grammar of the Lavongai language. Beaumont: Pacific Linguistics, The Australian National University.

Stirtz, Timothy M. 2012. A Grammar of Gaahmg: a Nilo-Saharan language of Sudan (LOT 296). Utrecht: LOT.

Tryon, Darrell T. 1967. Nengone grammar (Pacific Linguistics 6). Canberra: Australian National University. 